\title{
Performance-based design of multi-story buildings for a sustainable urban environment: a case study
}

\author{
Eugénio Rodrigues ${ }^{\mathrm{a}, *}$, Marco S. Fernandes ${ }^{\mathrm{a}}$, \\ Álvaro Gomes ${ }^{\mathrm{b}}$, Adélio Rodrigues Gaspar ${ }^{\mathrm{a}}$, José J. Costa ${ }^{\mathrm{a}}$ \\ ${ }^{a}$ ADAI, LAETA, Department of Mechanical Engineering, University of Coimbra, \\ Rua Luís Reis Santos, Pólo II, 3030-788 Coimbra, Portugal \\ ${ }^{b}$ INESC Coimbra, Department of Electrical and Computer Engineering, University of Coimbra, \\ Rua Sílvio Lima, Pólo II, 3030-290 Coimbra, Portugal
}

\begin{abstract}
This paper critically reviews the role of performance-based generative design in fast prototyping of buildings, describes the methodology of an automated generative layout design to produce complete building solutions, and presents a case study of multi-story buildings in urban context.

The proposed approach evolves the building design solutions by interacting with the city 3D geometry and evaluates the energy consumption for air-conditioning. The building designs take into consideration urban geometric constraints and objectives, such as alignment with surrounding buildings, urban lot area, and relative and absolute position of the generated elements. During the evaluation process, the urban context is considered for casting shadows and reflecting solar radiation.

The case study consists of six alternative 15-story buildings located in the city of São Paulo (Brazil), having commercial areas on the ground floor and two apartments per story on the remaining floors. The results show that, despite having similar apartments in every story, the urban context has a relevant impact on the buildings' energy performance. The difference between the apartments' best and worst energy performing stories ranges from $9 \%$ to $12 \%$ (ignoring the outlier story located in the first level), depending on the building solution. The results also show that the most energy efficient apartments' story is not located in the top or bottom floors, but rather at an intermediate level.
\end{abstract}

\section{Highlights}

- Urban context is added to an automatic floor plan generation procedure

- Alternative 15-story buildings are generated with residential and commercial spaces

- Energy consumption for air-conditioning is evaluated for every apartment

- Shadows and reflections from surroundings are evaluated during dynamic simulation

- Stories' energy performance vary from $9 \%$ to $12 \%$ despite having similar geometry

Keywords: generative design method, dynamic simulation, urban context, energy efficiency

This document has 6673 words.

\footnotetext{
${ }^{*}$ Corresponding author.

Email address: erodrigues@uc.pt (Eugénio Rodrigues)
} 


\section{Nomenclature}

EPSAP Evolutionary Program for the Space Allocation Problem

ES Evolution Strategy

FPD Floor Plan Design

HVAC Heating, Ventilation and Air-Conditioning

PVC Polyvinyl Chloride

SHC Stochastic Hill Climbing

\section{Introduction}

The sustainability of the built-environment is a complex subject in which interrelated systems have strong impact on the social, economic, and environment dimensions of the cities [1]. The aspects that influence the building performance are well known and largely studied, such as the form, compactness, orientation, thermophysical properties of the envelope elements, shading mechanisms, and ventilation strategies [2, 3, which can be optimized to improve the overall performance [4 7]. However, buildings should not be evaluated simply as an independent unit but rather understood as part of the urban fabric; surroundings alter the building performance [8] and the building itself influences the urban micro-climate [9].

As the complexity of building design demands knowledge in different fields and large number of alternatives to evaluate, performance-based design methods present themselves as promising tools to assist the building practitioners in the decision-making. These consist of finding novel solutions using building performance as guiding factor [10], where performance is assessed by simulation of a digital model set under predefined conditions [11. Such generative design methods are "capable of producing concepts and stimulating solutions based on robust and rigorous models of design conditions and performance criteria" [12], where an internal generative logic commands the creation of a range of alternative solutions for the building practitioners to compare and select the ones to be further developed [13. Besides allowing integration of synthesis and analytic phases of design, these automated and fast-prototyping design methods help to overcome designers' "limitations of knowledge or fixation" and automate tedium design tasks, thus "leaving more time for creative activities, and help reduce errors" [14].

Different approaches have been studied for the last two decades and were used to improve the structural dimensioning of buildings; to determine better building layout and building skin design; to dimension active systems, and to determine the most suitable construction system according to 
several performance criteria, such as construction and operation costs, energy use and production, indoor air quality, lighting, acoustics, building safety, and sustainability [13, 15-19].

One of the aspects covered by performance-based design methods is the study of the building layout, which consists of finding the best indoor arrangement of rooms such that it satisfies the functional program, as well as the topologic and geometric requirements. The process is commonly referred to as floor planning, space planning, or layout planning. The process of synthesizing design solutions may happen under conflicting objectives and requirements, sometimes vague and fuzzy user preferences. It occurs in the early stages of building design and it is a combinatorial problem in nature, thus the number of potential solutions increases exponentially as the complexity of the building design program grows. As the best performance-based decisions are made in the early stages, it is of outmost importance to explore alternative design solutions during the space planning phase, to help building practitioners to find the most promising designs to be further developed. Associated to each space and dwelling typology, there is information for occupancy, lighting, electric equipment, ventilation, hot water use, etc., therefore it is easy to produce detailed simulation models. Additionally, the urban context is a predominant factor for defining the building design geometry solution and it has a significant influence on the indoor thermal performance of the building due to shadowing and reflection effects of the surroundings [20]. Despite existing several algorithmic approaches to create building layout solutions, usually these are very abstract, missing several of the building designers' objectives and constraints. In the real world, building practitioners take into consideration several requirements and preferences related to urban context, such as building lot, construction area, building boundary, building alignments, visual obstructions, etc.; however, most of them are not considered in the generative design methods.

For instance, Koenig and Schneider [21] reviewed several works using different computational methods to solve buildings' layout problems and none of the analyzed works included surrounding concerns in the form of constraints or preferences to influence the generated designs. Likewise, Dino [22] implemented a 3D layout approach where solutions are generated to fit a provided building forms and then optimized using an evolutionary algorithm. In a later work, Dino and Üçoluk [23] explored the openings contribution to the energy consumption of each 3D building layout. While Wang et al. 24] implemented an automatic generation of rectangular floor plans by firstly determining the building dual graph and lastly adjusting the final graph by removing isolated rooms and satisfying the user-specified constraints. Duarte [25] used a shape grammar method to generate houses according to a particular architecture style of building layout. Hou and Stouffs [26] developed a shape grammar methodology for generic use, which can be applied to layout planning. 
None of these works mentions any concern with the urban context requirements or preferences.

However, Rodrigues et al. [27] carried out some preliminary studies to include them. The authors used a hybrid evolutionary approach to sequentially generate alternative building layouts for each lot in an urban quarter by substituting dummy buildings with fully detailed ones. This approach allowed to take into consideration the impact of the surrounding buildings that were not yet designed. Recently, Rodrigues et al. [28] studied the energy consumption of alternative building geometries with alternative construction systems in an urban quarter in Kuwait. Using an approach that starts at urban scale before reaching the building layout, Hua et al. [29] implemented an integer programming approach to find urban solutions according to several urban criteria; each urban solution has afterwards the building forms filled with space arrangements according to predefined templates. At urban design scale, Nault et al. [30] developed a decision-support tool to compare alternative neighborhood designs according to energy and daylight performance criteria.

Besides being helpful to building design practitioners, performance-based approaches can also be used to study some building performance phenomena, such as the impact of different building indexes [31, 32, to compare alternative construction systems [28], and to determine the best thermophysical properties of building elements [33 35].

However, the use of simulation in explorative contexts faces some challenges [36], such as the frequent mismatch between the available information and the required simulation model; the development lag between the simulation and the new building technology solutions; simulation outputs can be perceived as non-informative in the decision-making process; and accurate predictions can be time consuming, thus being incompatible with quick feedback. According to Frayssinet et al. [37, simulation of urban context has its own difficulties, such as the estimation of urban buildings' energy demand being more complex at the urban scale due to the amount of information necessary on the built structures; the diversity of occupants' behavior; and the specifications of urban environment, in particular the obstructions from surrounding constructions and surfaces that are specific for each building.

Hence, this paper presents a methodology that integrates some urban design requirements and incorporates other features that are missing or dispersed in the literature, and finally, a case study that exemplifies the potential of such approach. Although the case study consists of evaluating alternative high-rise urban buildings located in São Paulo, Brazil, the methodology is applicable to any building layout design problem and location. 


\section{Methodology}

The methodology consists of retrieving the urban geometry to specify the site specifications, defining the building design specifications, generating alternative building solutions, and evaluating each solution. The flowchart of the approach is depicted in Fig. 1 .

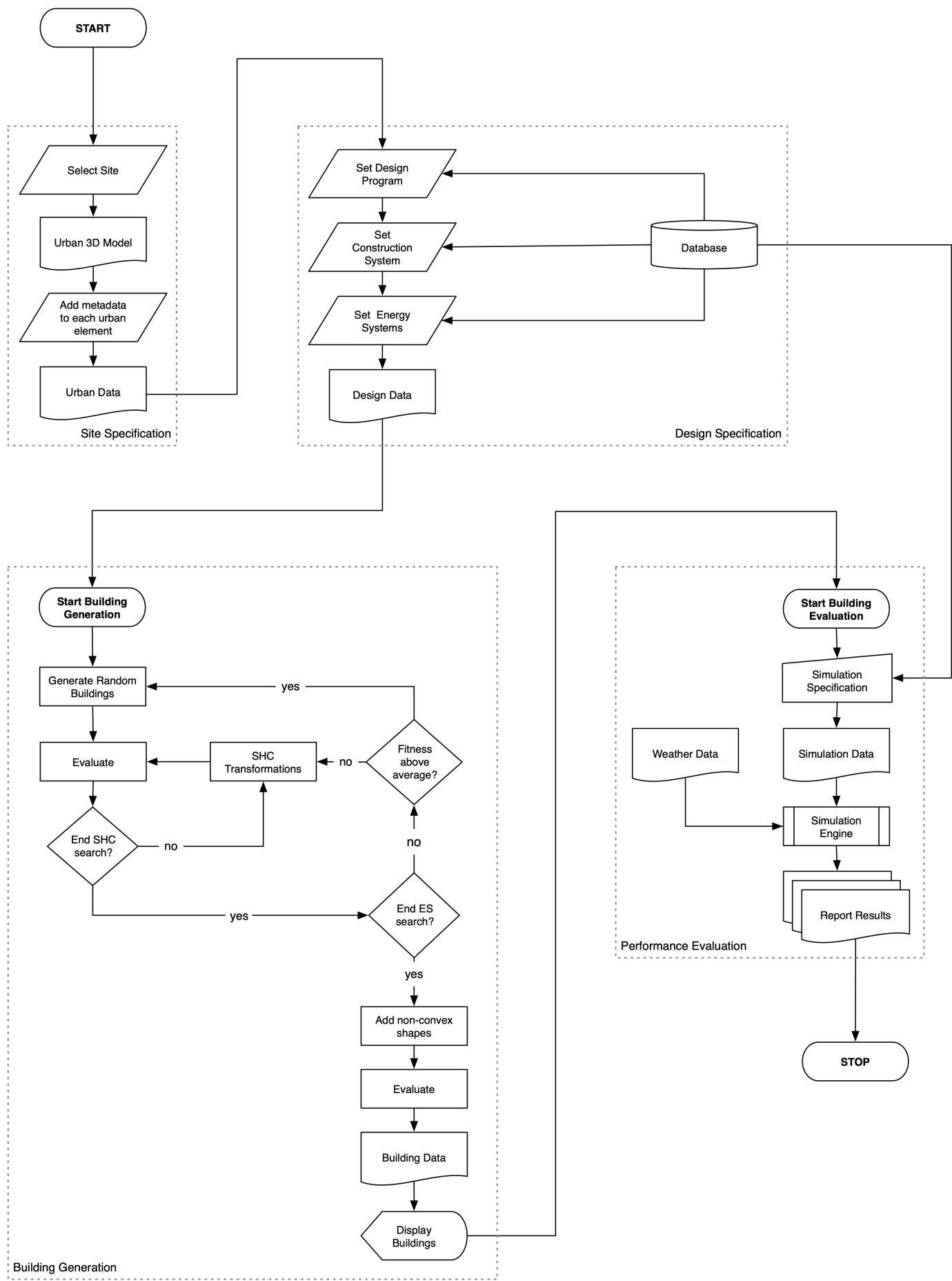

Fig. 1. Flowchart of methodology for building generation with performance evaluation. Four main stages are depicted; the outputs of the site and the design specification stages are the inputs for the algorithm, which proceeds to the buildings' generation and performance evaluations stages. 


\subsection{Site and design specifications}

In the initial phase, the limits of the urban surroundings are defined and the 3D objects created, represented by their boundary limits (BREP), which consist of connected surfaces that separate the solid from the non-solid parts. In this case study, the urban shape was downloaded from the Open Street Map website [38, but it can be obtained from other websites, existing city models, or manually created. The information is grouped into adjacent buildings, vegetation, and terrain; the terrain is vertically and horizontally split per story level and per grid (with a defined size), when the terrain is not plane. For each of these urban elements or group of elements, three metadata fields are added, which indicate if the building must be included in the generation process, if the building simulation evaluation is to be carried out, and finally, if the building should be visible. The reason for the inclusion of this metadata is, on one hand, to prevent the computation burden when i) calculating the overlapping of objects with the buildings that are not near the construction lot and do not have any impact in the generation process; and ii) determining the shadows overlapping by the polygon clipping algorithm phase of the dynamic simulation. On the other hand, this allows to simulate future scenarios when the adjacent buildings are not yet constructed and the user wishes to avoid openings facing them, or to calculate their influence on the building performance. Additionally, the user can also indicate the building boundary for each story level and the building alignment requirements - the urban geometry, building boundary, and building alignments are imported to the generative design method as a data exchange file. After the urban context specifications, the user defines the design program specification (see section 3), which includes information on the rooms, openings, occupation, artificial lighting, equipment, HVAC systems, and renewable energy systems. Most of this information is stored in a database as default data.

\subsection{Building generation}

With the site and design specifications as input data, the generative design method starts in the third phase. The building designs are created using a newer version of the Evolutionary Program for the Space Allocation Program (EPSAP) algorithm, presented in its earlier version in Refs. [39 41], which produces alternative space arrangements according to the user preferences and requirements. The new and updated floor plan representation scheme (depicted in Fig. 2 ) includes negative spaces (spaces that are considered voids but have connectivity and dimensional requirements), different roof types (depicted in Fig. 3. flat, gable, butterfly, mono-pitched, and other types), stairs that adjust the landing step dimensions to fit with neighboring spaces, individual story boundaries, 
and a newer opening frame type for garage spaces. Besides the new representation scheme, the current version uses an enlarged set of 18 penalty functions (described in Appendix A), nine of which are new: the layout alignment function, the layout fill construction and gross areas function, the story gross area function, the circulation space area function, the space fixed-position function, the space relative importance function, the opening accessibility function, the opening dimension function, and the opening fixed position function (the remaining ones are: the layout construction and gross area limits function, the space connectivity/adjacency function, the space overlap function, the space location function, the space dimensions function, the compactness function, the space overflow function, the opening overlap function, and the opening orientation function). The representation scheme includes new elements, such as negative spaces, element alignments, free position of interior openings, different types of openings' frame, and stairs can now have exterior openings. When the user specifies a number of repetitions of a particular story, such story is repeated in the end of the search process, thus reducing the computation time. In the end, dynamic simulation is carried out to perform energy evaluations of the generated solutions [42, 43].

The EPSAP algorithm consists of a two-stage approach that has an Evolution Strategy (ES) framework, where the mutation operation is replaced by a Stochastic Hill Climbing (SHC) method. The ES selection mechanism picks up for the next generation the individuals with a better fitness than the population average. The remaining individuals to complete the population are randomly created. The SHC stage is activated after the population of each new generation is completed and performs a set of random geometric and topologic transformations, such as translation, rotation, stretching, reflection, and swapping, which are applied to a single or a group of floor plan elements - openings, rooms, cluster of rooms, or to the whole floor plan. The algorithm stops when the termination condition is reached for both the ES and SHC stages, or when the maximum number of iterations is reached.

In the first stage, the ES initializes the population of individuals, where each individual is a floor plan design with randomly distributed objects (spaces, stairs, and/or elevators) with random dimension values. Then, each individual is assessed according to a cost function formulated in Appendix A. After the evaluation is complete, the second stage (SHC) is invoked and the ES stage remains suspended until the SHC stage reaches its termination condition. During this second stage, the individuals are subjected to a set of transformation operations. If a given transformation improves or maintains the individual fitness, the transformation is accepted; otherwise, it is rejected. The generative design process ends when the ES termination condition is also reached.

The transformation operators are implemented considering the characteristics of the space 


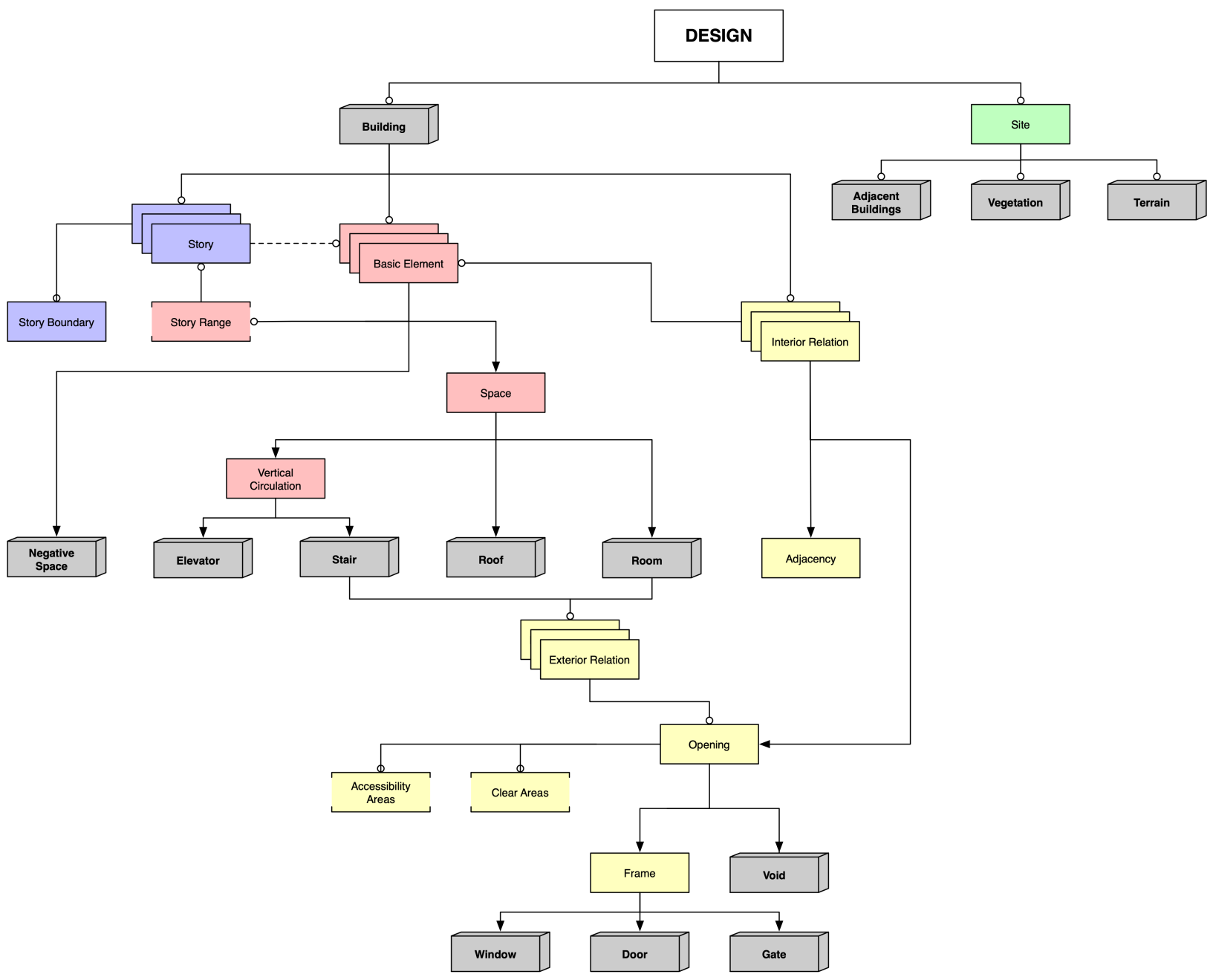

Fig. 2. New building representation scheme. Related objects are depicted with similar color. Gray-boxed objects are the building elements with geometric representation. Arrow-ended lines depict alternative elements, while circleended lines indicate the relation scheme.

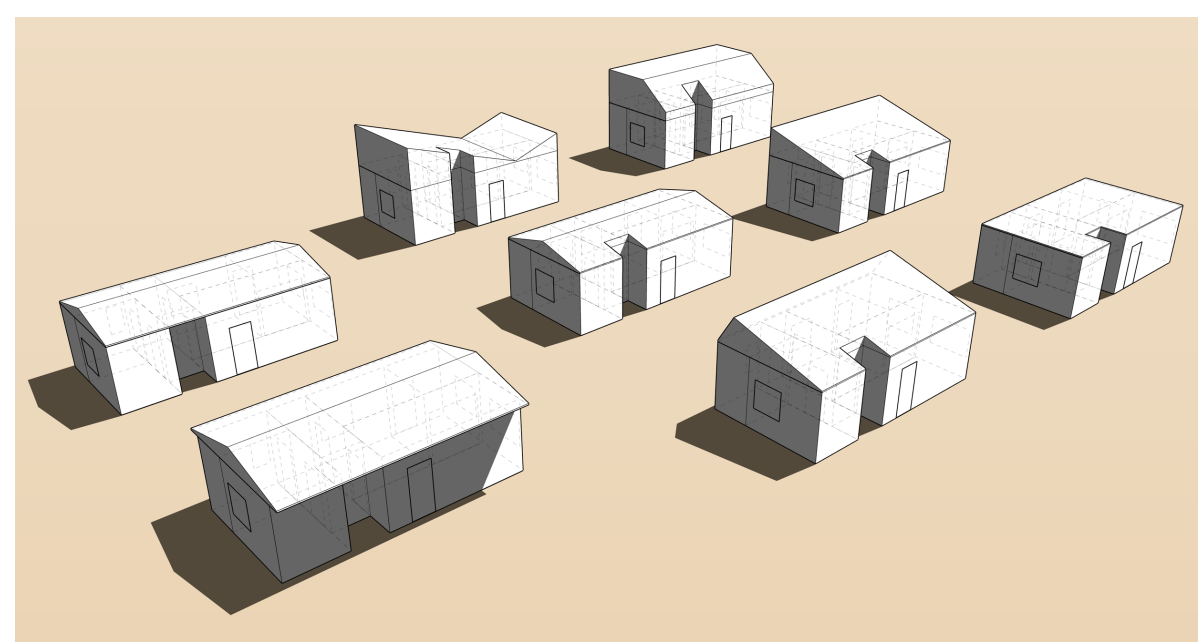

Fig. 3. Different types of roofs used in the generation algorithm. The roof is considered an attic treated as a thermal zone during simulation. The depicted types are gable, uneven gable, butterfly, mono-pitched, flat, and partial-flat roof type. The pitch angle, eave dimensions, bounded limits, height of the attic, orientation, and ridge position are all adjustable parameters. 
allocation problem and consist in introducing different geometric transformation actions. The transformation operators adapt their behavior according to the evolving stage of each floor plan design. Each one of the possible transformations may occur with different probability according to the performance of the individual in one of the penalty functions. For instance, during the initial phase of the evolution, the translation operator has more probability of being invoked to reduce the distance between spaces before resolving the overlap or the overflow of spaces. This probability depends on its past success in the last iterations. If the operator starts failing to improve an individual, it has less probability to be invoked. The transformation actions consist of translation, rotation, mirroring, stretching, swapping, splitting, and alignment. These actions are applied to a single or several objects at a time depending on the scale of the operation, such as the whole floor plan, a single level, a cluster, a space, or an opening. For example, the translation action may be used to move the whole floor plan, a single room, or an opening on a wall. The magnitude of the transformation is computed according to the size of the penalty given by the corresponding function. For instance, if two spaces do not satisfy the adjacency objective, then the distance of the translation is randomly determined up to the adjacency penalties' maximum value. Another important aspect of the transformation actions is their capability to adjust adjacent objects, within admissible dimension values, to accommodate the initial transformation. For example, when an object is moved to a new position and if it then overlaps with another object, the latter adapts its shape or will shift to accommodate the new position of the former object.

\subsection{Performance evaluation}

When the generation process concludes, the last phase initiates to evaluate the best generated designs' solutions (the ones with the lowest cost function value formulated in Eq. A.8) in Appendix A). The energy consumed in each space is aggregated according to the corresponding commercial space or apartment. The buildings' geometry, construction system, HVAC systems, energy production systems, hot water equipment, internal gains, lighting controls, and natural ventilation are parsed as input data to the EnergyPlus software (version 8.9.0), which, together with the weather data, calculates the energy consumption required for air-conditioning in each thermal zone (each space is a thermal zone).

Due to the consideration of urban surroundings, the shadow calculation method selected in EnergyPlus is the 'Average Over Days in Frequency' method, which performs the shadowing calculations (sun position, etc.) over a selected daytime period, in order to speed up the calculations. The calculations are performed for every 20 days throughout a weather run period; an average 
solar position is chosen and the solar factors (such as sunlit areas of surfaces) remain the same for that period of days.

Due to the shadowing algorithm, the number of shadows in a figure may grow quite large even with fairly reasonable looking structures; thus, allowing for too few figures in shadow overlaps may not result in accurate calculations [44]. Therefore, a maximum of 10000000 figures in shadow overlap calculations is chosen due to the great number of building surfaces in the current work.

Regarding the solar distribution, the option 'Full Exterior with Reflections' is selected in EnergyPlus. In this case, shadow patterns on exterior surfaces caused by detached shading, wings, overhangs, and exterior surfaces of all zones are computed, as well as shadowing by window and door reveals. The solar radiation beam entering the zone is assumed to fall entirely on the floor, where it is absorbed according to the floor's solar absorptance. Any radiation reflected by the floor is added to the transmitted diffuse radiation, which is assumed to be uniformly distributed on all interior surfaces. The zone heat balance is then applied at each surface and on the zone's air with the absorbed radiation being treated as an influx on the surface [44]. Relative to the simulation time step, the used value is $15 \mathrm{~min}$.

\section{Case study}

The generated buildings are located in São Paulo, Brazil $\left(-46.608^{\circ}\right.$ latitude and $-23.586^{\circ}$ longitude), in the cross road between Brigadeiro Jordão Street and Cipriano Barata Street. The map with the partial overlay of the 3D view from the lot is depicted in Fig. 4 - obtained from the website Open Street Map [38]. The single-story buildings that currently occupy the lot area are considered to be demolished to free up space for the new building. The generated buildings consist of commercial spaces in the ground floor and apartments in the upper floors. The height and facade alignments of the adjacent buildings, in particular the ones located in the North and East side of the lot, are satisfied. Regarding the building design program, on each of the upper stories, a three-bedroom and a two-bedroom apartment are served by a stair and an elevator. On the ground floor, stores and the building entrance must face one of the streets (West or South). The vertical circulations serve all stories and provide access to the roof.

\subsection{Design specifications}

The design program is for a 15-story building, with the residential stories $\left(L_{2 \cdots 14}\right)$ corresponding to a single floor plan repeated 13 times. The ground floor story $\left(L_{1}\right)$ has a $4.00 \mathrm{~m}$ height $\left(C^{l h}\right)$ and is dedicated to commerce, while the remaining stories $\left(L_{2}\right.$ to $\left.L_{15}\right)$ are $3.00 \mathrm{~m}$-high and include two 


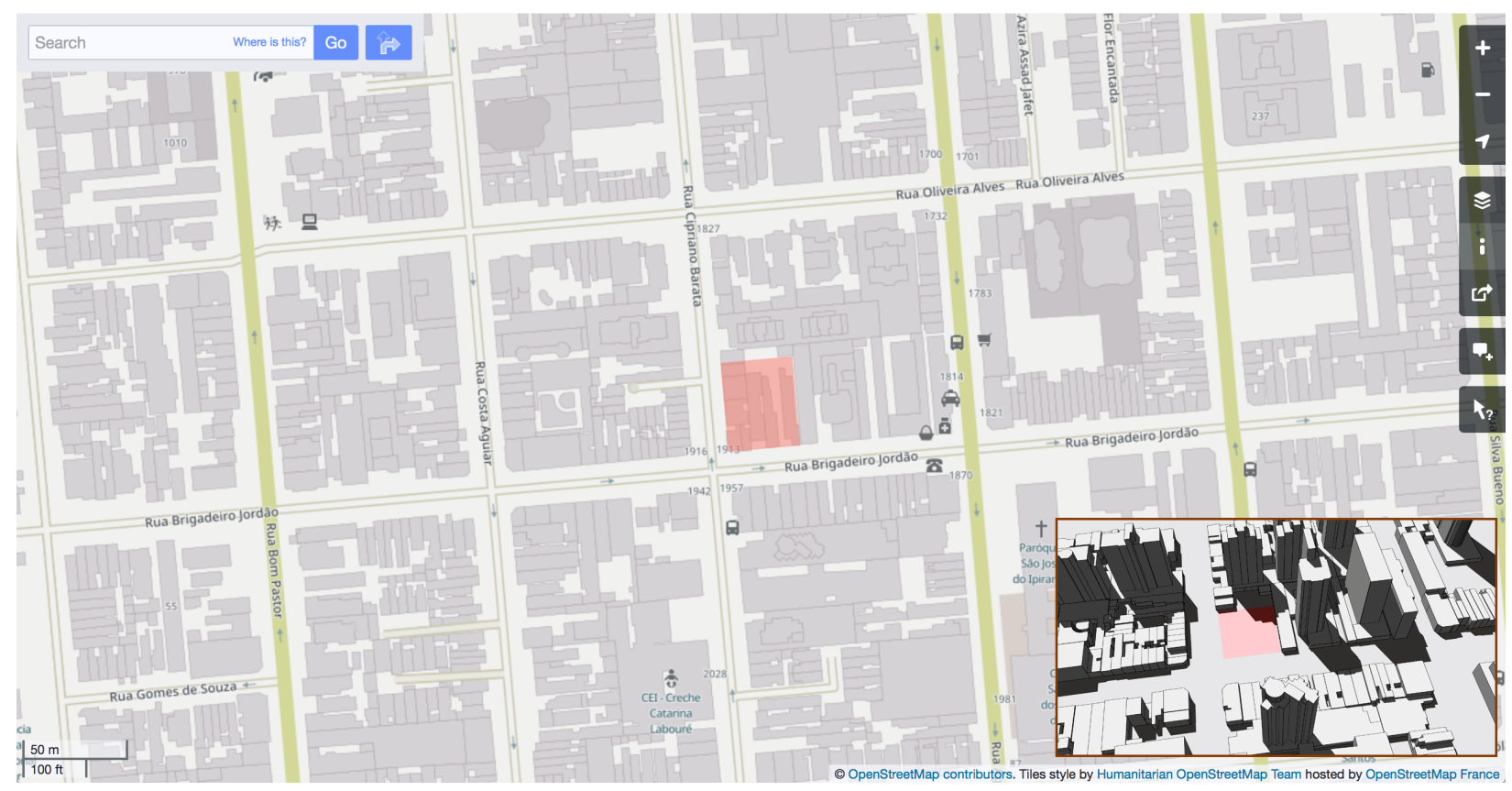

Fig. 4. Map of the lot location (marked in red) in São Paulo, Brazil. The 3D view of the urban geometry is depicted in the bottom right corner. Source: Open Street Map [38.

apartments per story (see Table 11). The last story $\left(L_{15}\right)$ provides access to the roof, having only the stairs and elevator shaft spaces. Each story has an aligned rectangular building boundary $\left(B_{j}\right)$ that corresponds to the lot area positioned at $x$-coordinate of $-79.30 \mathrm{~m}, y$-coordinate $-30.15 \mathrm{~m}$, $33.86 \mathrm{~m}$ width, and $35.02 \mathrm{~m}$ depth.

Table 1. Story specifications.

\begin{tabular}{lllc|lcccc}
\hline \multirow{2}{*}{ Story } & $C^{l n}$ & \multirow{2}{*}{$C^{l t}$} & $C^{l h}(\mathrm{~m})$ & $C^{b b}$ & $x(\mathrm{~m})$ & $y(\mathrm{~m})$ & width $(\mathrm{m})$ & depth $(\mathrm{m})$ \\
\hline$L_{1}$ & Street level & Entrance & 4.00 & $B_{1}$ & -79.30 & -30.15 & 33.86 & 35.02 \\
$L_{2 \cdots 14}$ & Private level & Upper & 3.00 & $B_{2 \cdots 14}$ & -79.30 & -30.15 & 33.86 & 35.02 \\
$L_{15}$ & Roof level & Upper & 3.00 & $B_{15}$ & -79.30 & -30.15 & 33.86 & 35.02 \\
\hline
\end{tabular}

The first-floor level $\left(L_{1}\right)$ comprises a shop $\left(S_{1}\right)$, two offices $\left(S_{2}\right.$ and $\left.S_{3}\right)$, and a coffeehouse $\left(S_{4}\right)$. In the residential stories $\left(L_{2}\right.$ to $\left.L_{14}\right)$, there are one three-bedroom apartment (Apartment T3) - a hall $\left(S_{7}\right)$, a living room $\left(S_{8}\right)$, a kitchen $\left(S_{9}\right)$, a bathroom $\left(S_{10}\right)$, a corridor $\left(S_{11}\right)$, a double bedroom $\left(S_{12}\right)$, two single bedrooms $\left(S_{13}\right.$ and $\left.S_{14}\right)$, and a second bathroom $\left(S_{15}\right)$ - and one two-bedroom apartment (Apartment T2) - a hall $\left(S_{16}\right)$, a living room $\left(S_{17}\right)$, a kitchen $\left(S_{18}\right)$, a bathroom $\left(S_{19}\right)$, a corridor $\left(S_{20}\right)$, a double bedroom $\left(S_{21}\right)$, and one single bedroom $\left(S_{22}\right)$. Each story is served by a stair $\left(S_{5}\right)$ and an elevator $\left(S_{6}\right)$. Table 2 lists all the specified requirements. For example, the living room $\left(S_{8}\right)$ is of function type Living $\left(C^{s f}\right)$, with relative importance of $\operatorname{Max}\left(C^{r i}\right)$, repeated on every story from $L_{2}$ to $L_{14}\left(C^{s l}, C^{s u}\right)$, having a minimum side dimension of $3.40 \mathrm{~m}\left(C^{s s}\right)$, and side limits of 1.7 for the smaller side $\left(C^{s s r}\right)$, and 2.0 for the larger side $\left(C^{s l r}\right)$ of the room.

Each room may have exterior openings (windows or doors). For instance, Office A $\left(S_{2}\right)$ has 
Table 2. Rooms' geometry and topologic specifications.

\begin{tabular}{|c|c|c|c|c|c|c|c|c|c|}
\hline Apart. & Room & $C^{s n}$ & $C^{s f}$ & $C^{r i}$ & $C^{s l}$ & $C^{s u}$ & $C^{s s}(\mathrm{~m})$ & $C^{s s r}$ & $C^{s l r}$ \\
\hline- & $S_{1}$ & Shop & Living & None & $L_{1}$ & $L_{1}$ & 4.00 & 1.7 & 2.0 \\
\hline- & $S_{2}$ & Office A & Living & None & $L_{1}$ & $L_{1}$ & 4.00 & 1.7 & 2.0 \\
\hline- & $S_{3}$ & Office B & Living & None & $L_{1}$ & $L_{1}$ & 4.00 & 1.7 & 2.0 \\
\hline- & $S_{4}$ & coffeehouse & Living & None & $L_{1}$ & $L_{1}$ & 4.00 & 1.7 & 2.0 \\
\hline- & $S_{5}$ & Stair & Circulation & - & $L_{1}$ & $L_{15}$ & - & - & - \\
\hline- & $S_{6}$ & Elevator & Circulation & - & $L_{1}$ & $L_{15}$ & - & - & - \\
\hline \multirow{9}{*}{$\mathrm{T} 3$} & $S_{7}$ & Hall & Circulation & Min & $L_{2} / L_{14}$ & $L_{2} / L_{14}$ & 2.70 & $\{2.0,3.0\}$ & $\{3.0,1.5\}$ \\
\hline & $S_{8}$ & Living room & Living & Max & $L_{2} / L_{14}$ & $L_{2} / L_{14}$ & 3.40 & 1.7 & 2.0 \\
\hline & $S_{9}$ & Kitchen & Service & Mid & $L_{2} / L_{14}$ & $L_{2} / L_{14}$ & 2.60 & 1.7 & 2.0 \\
\hline & $S_{10}$ & Bathroom & Service & Min & $L_{2} / L_{14}$ & $L_{2} / L_{14}$ & 2.00 & 1.7 & 2.0 \\
\hline & $S_{11}$ & Corridor & Circulation & Min & $L_{2} / L_{14}$ & $L_{2} / L_{14}$ & 2.00 & $\{2.0,3.0\}$ & $\{3.0,1.5\}$ \\
\hline & $S_{12}$ & Double bedroom & Living & High & $L_{2} / L_{14}$ & $L_{2} / L_{14}$ & 3.00 & 1.7 & 2.0 \\
\hline & $S_{13}$ & Single bedroom & Living & Mid & $L_{2} / L_{14}$ & $L_{2} / L_{14}$ & 2.80 & 1.7 & 2.0 \\
\hline & $S_{14}$ & Single bedroom & Living & Mid & $L_{2} / L_{14}$ & $L_{2} / L_{14}$ & 2.80 & 1.7 & 2.0 \\
\hline & $S_{15}$ & Bathroom & Service & Min & $L_{2} / L_{14}$ & $L_{2} / L_{14}$ & 2.20 & 1.7 & 2.0 \\
\hline \multirow{7}{*}{$\mathrm{T} 2$} & $S_{16}$ & Hall & Circulation & Min & $L_{2} / L_{14}$ & $L_{2} / L_{14}$ & 2.70 & $\{2.0,3.0\}$ & $\{3.0,1.5\}$ \\
\hline & $S_{17}$ & Living room & Living & Max & $L_{2} / L_{14}$ & $L_{2} / L_{14}$ & 3.40 & 1.7 & 2.0 \\
\hline & $S_{18}$ & Kitchen & Service & Mid & $L_{2} / L_{14}$ & $L_{2} / L_{14}$ & 2.60 & 1.7 & 2.0 \\
\hline & $S_{19}$ & Bathroom & Service & Min & $L_{2} / L_{14}$ & $L_{2} / L_{14}$ & 2.20 & 1.7 & 2.0 \\
\hline & $S_{20}$ & Corridor & Circulation & Min & $L_{2} / L_{14}$ & $L_{2} / L_{14}$ & 2.00 & $\{2.0,3.0\}$ & $\{3.0,1.5\}$ \\
\hline & $S_{21}$ & Double bedroom & Living & High & $L_{2} / L_{14}$ & $L_{2} / L_{14}$ & 3.00 & 1.7 & 2.0 \\
\hline & $S_{22}$ & Single bedroom & Living & Mid & $L_{2} / L_{14}$ & $L_{2} / L_{14}$ & 2.80 & 1.7 & 2.0 \\
\hline
\end{tabular}

an opening $\left(\mathrm{Oe}_{2}\right)$ of type Window/Door $\left(\mathrm{C}^{\text {oet }}\right)$, with $3.0 \mathrm{~m}$ width $\left(C^{\text {oew }}\right)$, $3.4 \mathrm{~m}$ height $\left(C^{\text {oeh }}\right)$, elevated $0.0 \mathrm{~m}$ from the floor $\left(C^{\text {oev }}\right)$, and preferable orientation South or West $\left(C^{\text {oeo }}\right)$. Table 3 lists all exterior openings in the design program per room $\left(C^{o s}\right)$.

Table 3. Geometry specifications of exterior openings.

\begin{tabular}{lllcccl}
\hline$C^{\text {os }}$ & Opening & $C^{\text {oet }}$ & $C^{\text {oew }}(\mathrm{m})$ & $C^{\text {oeh }}(\mathrm{m})$ & $C^{\text {oev }}(\mathrm{m})$ & $C^{\text {oeo }}$ \\
\hline$S_{1}, S_{2}, S_{3}, S_{4}$ & $O e_{1 \cdots 4}$ & Window/Door & 3.00 & 3.40 & 0 & $\{$ South or West $\}$ \\
$S_{5}$ & $O e_{5}$ & Window/Door & 1.60 & 2.40 & 0 & $\{$ South or West $\}$ \\
$S_{9}, S_{18}$ & $O e_{6 \cdots 7}$ & Window & 1.20 & 1.20 & 1.00 & - \\
$S_{8}, S_{17}$ & $O e_{8} \cdots 9$ & Window & 1.80 & 1.20 & 1.00 & - \\
$S_{12}, S_{13}, S_{14}, S_{21}, S_{22}$ & $O e_{10 \cdots 14}$ & Window & 1.20 & 1.20 & 1.00 & - \\
$S_{15}$ & $O e_{15}$ & Window & 0.80 & 1.20 & 1.00 & - \\
\hline$C^{\text {os }}$ - space, $C^{\text {oet }}-$ opening type, $C^{\text {oew }}-$ minimum width, $C^{\text {oeh }}-$ minimum height, \\
$C^{\text {oev }- \text { vertical position, } C^{\text {oeo }}-\text { orientation }}$ \\
\hline
\end{tabular}

Besides exterior openings, the rooms may have adjacency or connectivity requirements; e.g., the $O i_{1}$ is an adjacency between the rooms $S_{1}$ and $S_{5}$, while the interior opening $O i_{3}$ is of type Door $\left(C^{\text {oit }}\right)$, with $0.9 \mathrm{~m}$ width $\left(C^{\text {oiw }}\right), 2.0 \mathrm{~m}$ height $\left(C^{\text {oih }}\right)$, and $0.0 \mathrm{~m}$ elevation from the floor $\left(C^{\text {oiv }}\right)$, which connects room $S_{5}\left(C^{o i a}\right)$ to room $S_{6}\left(C^{o i b}\right)$. Table 4 lists all the interior openings in the building.

The compactness of the building is controlled using clusters (see Table 5). The cluster $G_{3}^{c}$ defines the rooms in Apartment T3 and cluster $G_{4}^{c}$ in Apartment T2.

The building alignments are defined by two linear requirements for the cluster $G_{1}^{a}$, which is defined by the residential and vertical circulation spaces. The first requirement sets a horizontal 
Table 4. Interior openings geometry and topologic specifications.

\begin{tabular}{|c|c|c|c|c|c|c|}
\hline Opening & $C^{o i t}$ & $C^{o i a}$ & $C^{o i b}$ & $C^{\text {oiw }}(\mathrm{m})$ & $C^{o i h}(\mathrm{~m})$ & $C^{\text {oiv }}(\mathrm{m})$ \\
\hline$O i_{1}$ & Adjacency & $S_{5}$ & $S_{1}$ & - & - & - \\
\hline$O i_{2}$ & Adjacency & $S_{5}$ & $S_{3}$ & - & - & - \\
\hline$O i_{3}$ & Door & $S_{5}$ & $S_{6}$ & 0.90 & 2.00 & 0.0 \\
\hline$O i_{4}$ & Door & $S_{5}$ & $S_{7}$ & 0.90 & 2.00 & 0.0 \\
\hline$O i_{5}$ & Door & $S_{5}$ & $S_{16}$ & 0.90 & 2.00 & 0.0 \\
\hline$O i_{6}$ & Door & $S_{7}$ & $S_{8}$ & 0.90 & 2.00 & 0.0 \\
\hline$O i_{7}$ & Door & $S_{7}$ & $S_{9}$ & 0.90 & 2.00 & 0.0 \\
\hline$O i_{8}$ & Door & $S_{7}$ & $S_{10}$ & 0.90 & 2.00 & 0.0 \\
\hline$O i_{9}$ & Door & $S_{7}$ & $S_{11}$ & 0.90 & 2.00 & 0.0 \\
\hline$O i_{10}$ & Door & $S_{11}$ & $S_{12}$ & 0.90 & 2.00 & 0.0 \\
\hline$O i_{11}$ & Door & $S_{11}$ & $S_{13}$ & 0.90 & 2.00 & 0.0 \\
\hline$O i_{12}$ & Door & $S_{11}$ & $S_{14}$ & 0.90 & 2.00 & 0.0 \\
\hline$O i_{13}$ & Door & $S_{11}$ & $S_{15}$ & 0.90 & 2.00 & 0.0 \\
\hline$O i_{14}$ & Door & $S_{16}$ & $S_{17}$ & 0.90 & 2.00 & 0.0 \\
\hline$O i_{15}$ & Door & $S_{16}$ & $S_{18}$ & 0.90 & 2.00 & 0.0 \\
\hline$O i_{16}$ & Door & $S_{16}$ & $S_{19}$ & 0.90 & 2.00 & 0.0 \\
\hline$O i_{17}$ & Door & $S_{16}$ & $S_{20}$ & 0.90 & 2.00 & 0.0 \\
\hline$O i_{18}$ & Door & $S_{20}$ & $S_{21}$ & 0.90 & 2.00 & 0.0 \\
\hline$O i_{19}$ & Door & $S_{20}$ & $S_{22}$ & 0.90 & 2.00 & 0.0 \\
\hline
\end{tabular}

Table 5. Rooms' compactness specifications.

\begin{tabular}{cl}
\hline Clusters & Rooms \\
\hline$G_{1}^{c}$ & $\left\{S_{1}, S_{2}\right\}$ \\
$G_{2}^{c}$ & $\left\{S_{3}, S_{4}\right\}$ \\
$G_{3}^{c}$ & $\left\{S_{7}, S_{8}, S_{9}, S_{10}, S_{11}, S_{12}, S_{13}, S_{14}, S_{15}\right\}$ \\
$G_{4}^{c}$ & $\left\{S_{16}, S_{17}, S_{18}, S_{19}, S_{20}, S_{21}, S_{22}\right\}$ \\
\hline
\end{tabular}

alignment at the coordinate $y=-22.00 \mathrm{~m}$, with the building occupying the Northern side. The second requirement defines a vertical alignment at the ordinate $x=-70.00 \mathrm{~m}$, having the building positioned in the East side of the alignment. Table 6 summarizes the alignment specifications.

Table 6. Alignment specifications.

\begin{tabular}{clllc}
\hline Cluster & Rooms & $C^{a o}$ & $C^{a s}$ & $C^{a v}(\mathrm{~m})$ \\
\hline \multirow{2}{*}{$G_{1}^{a}$} & $\left\{S_{5}, S_{6}, S_{7}, S_{8}, S_{9}, S_{10}, S_{11}, S_{12}, S_{13}\right.$, & Horizontal & North & -22.00 \\
& $\left.S_{14}, S_{15}, S_{16}, S_{17}, S_{18}, S_{19}, S_{20}, S_{21}, S_{22}\right\}$ & Vertical & East & -70.00 \\
\hline
\end{tabular}

\subsection{Construction system}

The building has strong inertia with current material properties. Its construction elements and respective properties are presented in Table 7. These meet the Brazilian legal limits for the thermal transmittance, and follow the specifications of exterior opaque elements presented in [45] (electric energy consumption optimization study regarding the performance of solar protection systems in a passive building in Brazil). 
Table 7. Construction element specifications.

\begin{tabular}{|c|c|c|c|c|c|c|c|}
\hline Element & Layer & Thickness (m) & $k\left(\mathrm{~W} \cdot \mathrm{m}^{-1} \cdot \mathrm{K}^{-1}\right)$ & $\rho\left(\mathrm{kg} \cdot \mathrm{m}^{-3}\right)$ & $c_{p}\left(\mathrm{~J} \cdot \mathrm{kg}^{-1} \cdot \mathrm{K}^{-1}\right)$ & $U\left(\mathrm{~W} \cdot \mathrm{m}^{-2} \cdot \mathrm{K}^{-1}\right)$ & SHGC \\
\hline \multirow{3}{*}{ Interior wall } & Finishing layer & 0.02 & 0.22 & 950 & 840 & \multirow{3}{*}{4.50} & - \\
\hline & Structural layer & 0.07 & 1.73 & 2243 & 836.8 & & \\
\hline & Finishing layer & 0.02 & 0.22 & 950 & 840 & & \\
\hline \multirow{4}{*}{ Interior slab } & Finishing layer & 0.02 & 0.22 & 950 & 840 & \multirow{4}{*}{2.84} & - \\
\hline & Structural layer & 0.2 & 1.73 & 2245.6 & 836.8 & & \\
\hline & Regulation layer & 0.01 & 0.22 & 950 & 840 & & \\
\hline & Finishing layer & 0.02 & 0.2 & 825 & 2385 & & \\
\hline \multirow{5}{*}{ Exterior wall } & Finishing layer & 0.02 & 0.431 & 1250 & 1088 & \multirow{5}{*}{0.43} & - \\
\hline & Structural layer & 0.11 & 1.25 & 2082.4 & 920.5 & & \\
\hline & Insulation layer & 0.08 & 0.04 & 32.1 & 836.8 & & \\
\hline & Structural layer & 0.15 & 1.73 & 2243 & 836.8 & & \\
\hline & Finishing layer & 0.02 & 0.22 & 950 & 840 & & \\
\hline \multirow{6}{*}{ Suspended slab } & Finishing layer & 0.02 & 0.431 & 1250 & 1088 & \multirow{6}{*}{0.42} & - \\
\hline & Structural layer & 0.11 & 1.25 & 2082.4 & 920.5 & & \\
\hline & Insulation layer & 0.08 & 0.04 & 32.1 & 836.8 & & \\
\hline & Structural layer & 0.2 & 1.73 & 2245.6 & 836.8 & & \\
\hline & Regulation layer & 0.01 & 0.22 & 950 & 840 & & \\
\hline & Finishing layer & 0.02 & 0.2 & 825 & 2385 & & \\
\hline \multirow{5}{*}{ Ground floor } & Structural layer & 0.2 & 1.73 & 2245.6 & 836.8 & \multirow{5}{*}{0.44} & - \\
\hline & Insulation layer & 0.08 & 0.04 & 32.1 & 836.8 & & \\
\hline & Filling layer & 0.02 & 0.8 & 1600 & 840 & & \\
\hline & Regulation layer & 0.01 & 0.22 & 950 & 840 & & \\
\hline & Finishing layer & 0.02 & 0.2 & 825 & 2385 & & \\
\hline \multirow{5}{*}{ Roof } & Finishing layer & 0.15 & 1.44 & 881 & 1673.6 & \multirow{5}{*}{0.35} & - \\
\hline & Regulation layer & 0.01 & 0.19 & 1121.3 & 1673.6 & & \\
\hline & Insulation layer & 0.1 & 0.04 & 91.3 & 836.8 & & \\
\hline & Structural layer & 0.2 & 1.73 & 2245.6 & 836.8 & & \\
\hline & Finishing layer & 0.02 & 0.22 & 950 & 840 & & \\
\hline \multirow{3}{*}{ Interior door } & Finishing layer & 0.005 & 0.2 & 825 & 2385 & \multirow{3}{*}{2.01} & - \\
\hline & Structural layer & 0.03 & 0.067 & 430 & 1260 & & \\
\hline & Finishing layer & 0.005 & 0.2 & 825 & 2385 & & \\
\hline Exterior door & Structural layer & 0.04 & 0.2 & 825 & 2385 & 5.00 & - \\
\hline Exterior window & - & 0.06 & - & - & - & 2.40 & 0.6 \\
\hline
\end{tabular}

\subsection{Occupancy, equipment, lighting, and HVAC specifications}

The occupancy patterns and the operation schedules of equipment, lighting and HVAC for each space typology are based on the Brazilian 'Technical Regulation for the Energy Efficiency Level of Residential Buildings' (RTQ-R) [46], on the Brazilian 'Technical Regulation for the Energy Efficiency Level of Commercial, Service and Public Buildings' (RTQ-C) [47, and on the spaces' typology.

Each apartment is considered as a single-family dwelling occupied by three (T2) or four (T3) people. The commercial spaces - coffeehouse, shop, office 1 and office 2 - are occupied by a maximum of thirty, four, three and five people at the peak of occupancy, respectively. The shop space represents a small family shop (e.g., cellphone store, insurance store, barber shop), usually found in these residential neighborhoods, which are characterized by local commerce in the ground floor and by a small number of clients and employees - thus the small occupancy level considered. The occupancy patterns in the different spaces throughout the day (for workdays and weekends) are depicted in Fig. 5. The internal heat gains due to occupancy are also related to the maximum 
number of people per zone and the respective activity level, which are presented in Table 8 .

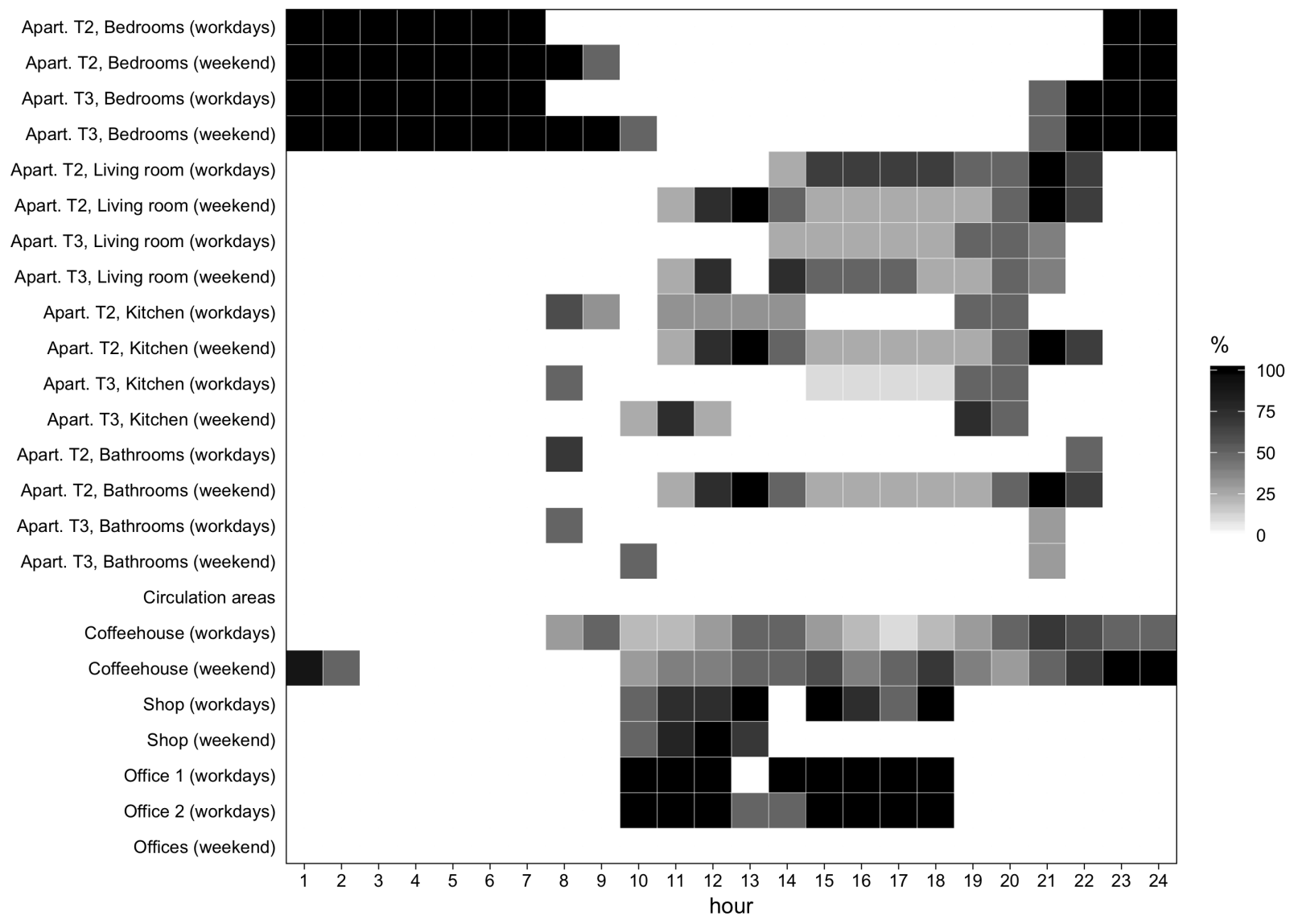

Fig. 5. General occupancy pattern in the building zones.

Table 8. Maximum number of people per zone and corresponding activity levels.

\begin{tabular}{lcc}
\hline Zone type & Max number of people & \\
& & Activity level $\left(\mathrm{W} \cdot\right.$ person $\left.^{-1}\right)$ \\
\hline Double bedroom & 2 & 81 \\
Single bedroom & 1 & 81 \\
Apart. T2, Living room & 3 & 108 \\
Apart. T3, Living room & 4 & 129 \\
Apart. T2, Kitchen & 3 & 124 \\
Apart. T3, Kitchen & 4 & 190 \\
Bathrooms & 1 & 171 \\
Coffeehouse & 30 & 160 \\
Shop & 4 & 130 \\
Office 1 & 3 & 115 \\
Office 2 & 5 & 115 \\
\hline${ }^{a}-$ Regarding the building inhabitants accessing each zone, and not necessarily the number \\
of occupants simultaneously in the zone. The occupant's distribution is defined together \\
with the proper occupancy schedules. \\
\hline
\end{tabular}

The internal gains due to electric lights are defined by the maximum design lighting level for each zone type, as presented in Table 9, and the corresponding usage schedules, depicted in Fig. 6, according to RTQ-R [46] and RTQ-C [47].

The methodology proposed in Annex I of RTQ-R is used as a basis for the shading profile of the window openings. The method aims to assist the sizing of solar protection devices, regarding the shading variable of the envelope performance equation for spaces that do not present shutters, 
Table 9. Maximum design lighting levels for each zone type.

\begin{tabular}{lc}
\hline Zone type & Design lighting level $\left(\mathrm{W} \cdot \mathrm{m}^{-2}\right)$ \\
\hline Bedrooms & 5 \\
Living room & 6 \\
Kitchen & 6 \\
Bathrooms & 6 \\
Coffeehouse & 7 \\
Shop & 18.1 \\
Offices & 11.9 \\
\hline
\end{tabular}

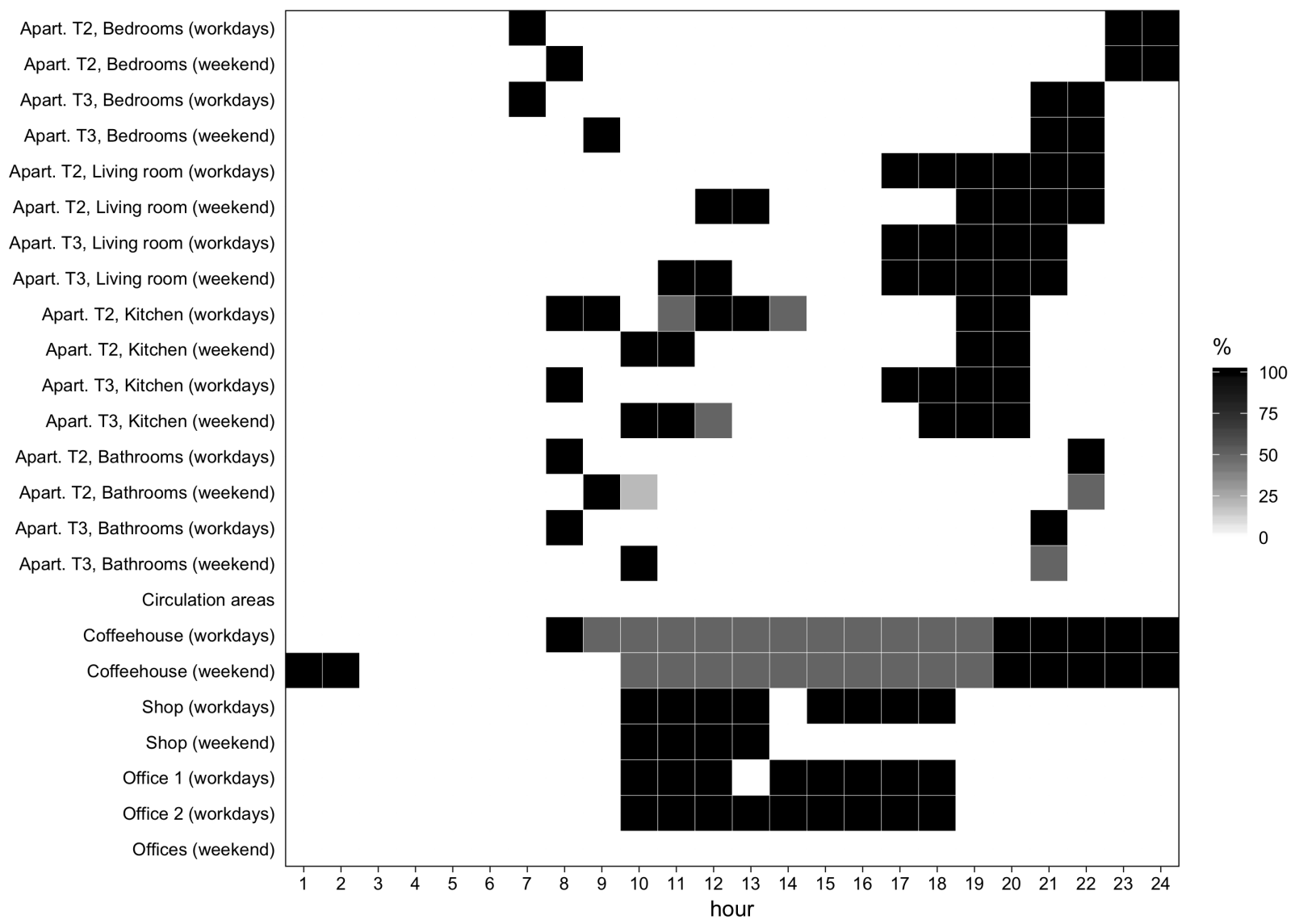

Fig. 6. Electric light schedule in each zone.

and that are shaded by overhanging, balcony or horizontal brise soleil elements [46]. Hence, it should be made clear that the referred methodology does not present a window shading standard, serving here only to assist in defining the shading profile of the window openings. Thus, according to the RTQ-R, small window openings (less than $25 \%$ of the floor area) should be shaded when the outdoor temperature exceeds $\operatorname{Tn}]^{1}+3{ }^{\circ} \mathrm{C}$ and the incident solar radiation surpasses $600 \mathrm{~W} \cdot \mathrm{m}^{-2}$; and large window openings (above $25 \%$ of the floor area) should be shaded when the outdoor temperature exceeds $T n+3{ }^{\circ} \mathrm{C}$ or the incident solar radiation surpasses $600 \mathrm{~W} \cdot \mathrm{m}^{-2}$. However, when selecting two shading setpoint types (temperature and radiation) in EnergyPlus, it allows to consider them only paired, not independent from each other. Therefore, and since geometry

\footnotetext{
${ }^{1} \mathrm{Tn}$ - monthly neutral temperature: $\mathrm{Tn}=0.31 \times T e+17.6\left({ }^{\circ} \mathrm{C}\right)$, where $T e$ represents the monthly air temperature $\left({ }^{\circ} \mathrm{C}\right)$. In this work, the $T e$ values were obtained from the climatic data files for the city of São Paulo.
} 
restrictions prevent glazing areas above $25 \%$ of the floor area, only the first operation mode is considered: shading whenever $T n+3{ }^{\circ} \mathrm{C}$ and $600 \mathrm{~W} \cdot \mathrm{m}^{-2}$. Moreover, EnergyPlus also does not allow for variable setpoints. For that reason, an annual average $T n$ value of $27.24^{\circ} \mathrm{C}$ was computed, which is considered in this work. Hence, whenever the outdoor temperature exceeds $30.24^{\circ} \mathrm{C}$ and the incident solar radiation exceeds $600 \mathrm{~W} \cdot \mathrm{m}^{-2}$, the window shadings are activated. The shadings are assumed to be PVC roller shutters in all the apartments' windows and internal cloth shades are considered in the offices' windows. The coffeehouse and the shop are assumed not having window shadings.

The internal heat gains due to electric equipment depend on the maximum design wattage levels of the equipment in each zone. A constant value of $1.5 \mathrm{~W} \cdot \mathrm{m}^{-2}$ is considered in the apartments' living rooms, as pointed in RTQ-R [46]. For kitchen zones, a constant value of $2.0 \mathrm{~W} \cdot \mathrm{m}^{-2}$ is assumed [45]. Regarding the commercial spaces, the electric equipment heat gains depend on the maximum design wattage levels (Table 10), which are based on the building zone typology and the appliances typically found in each space [48], and the respective usage schedules (Fig. 7). These schedules are based on the zones' typology and occupancy.

Table 10. Total heat gains from electric equipment in each commercial space.

\begin{tabular}{lrc}
\hline & \multicolumn{2}{c}{ Design level } \\
Zone type & $\mathrm{W}$ & $\mathrm{W} \cdot \mathrm{m}^{-2}$ \\
\hline Coffeehouse & 3450 & - \\
Shop & 200 & - \\
Offices & - & 8.61 \\
\hline
\end{tabular}

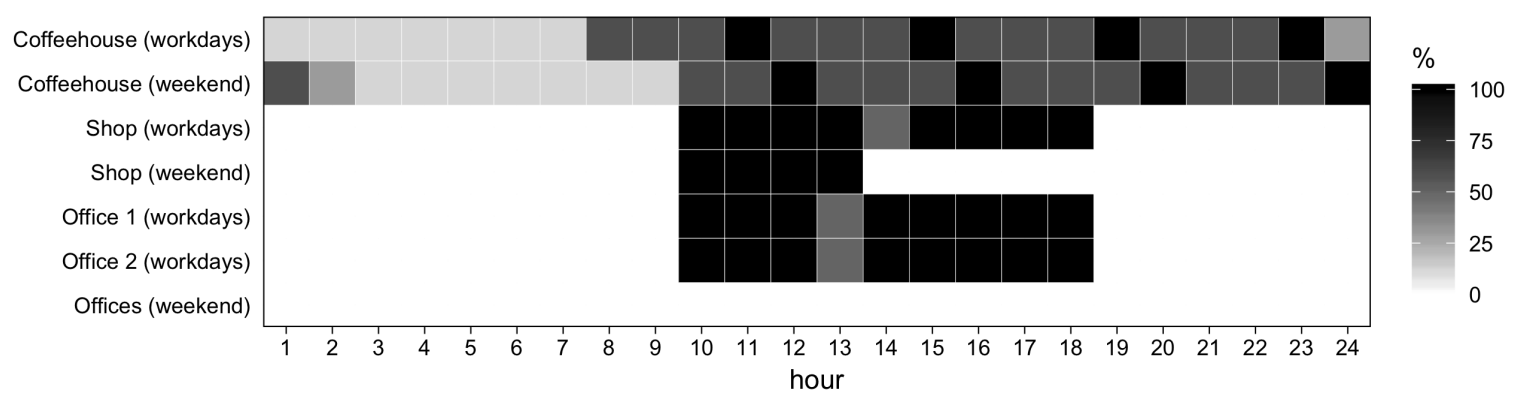

Fig. 7. Electric equipment schedules in each commercial space.

Regarding infiltration specifications, constant values of 0.2 air changes per hour (ACH) and $0.1 \mathrm{ACH}$ are considered for the outdoor air infiltration into zones with and without exterior openings, respectively, while a nominal $1.0 \mathrm{ACH}$ exhaust ventilation is considered for kitchens and bathrooms, with the flow rate profile presented in Fig. 8, which is based on each space occupation profile (Fig. 5).

Concerning natural ventilation, RTQ-R [46] refers that all dwelling spaces with ventilation 


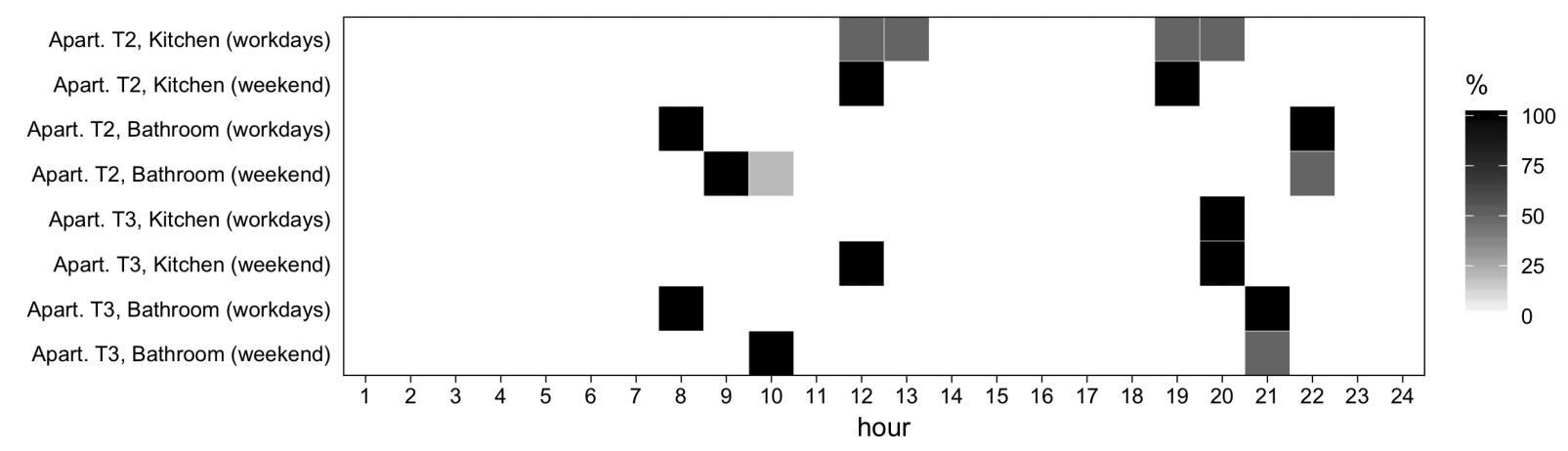

Fig. 8. Exhaust ventilation schedules in kitchens and bathrooms.

openings must be modeled in the natural ventilation mode, operating with the following specifications: from 9:00 to 21:00, and only when the temperature inside is above $20.0^{\circ} \mathrm{C}$ and above the outdoor temperature. Accordingly, a natural ventilation (wind and stack) object is applied to all apartments' windows, with the above defined specifications. The minimum opening level of each window depends on its own type. According to the Annex II of RTQ-R [46], a $45 \%$ opening is considered for sliding windows (circulation areas, living rooms, bedrooms and kitchens) and $90 \%$ for pivoted windows (bathrooms). Regarding the commercial spaces, a nominal 1.5 ACH was considered in the coffeehouse and in the shop, due to the constant entering and exiting of clients, with ventilation profiles equivalent to the light schedules defined for these spaces (Fig. 6), as lighting is considered to be on during all working hours.

Regarding climatization specifications, the living room and the bedrooms are the only apartments' spaces where heating and cooling must be considered (unitary split system air-conditioning) [46]. For this purpose, the system and zone unitary model of EnergyPlus is used, which allows to simulate standard unitary air-conditioning equipment in each zone. According to RTQ-R [46], the air temperature thermostat setpoints assumed for cooling and heating are $24.0^{\circ} \mathrm{C}$ and $22.0^{\circ} \mathrm{C}$, respectively; the cooling and heating equipment's coefficient of performance are 3 and 2.75 , respectively; and each equipment has a $70 \%$ fan efficiency, $90 \%$ motor efficiency and runs continuously between 21:00 and 9:00. Accordingly, the corresponding heating/cooling availability schedules for each zone are equivalent to the occupation schedules defined for the respective zones (Fig. 5), within the referred time boundaries.

Regarding the commercial spaces, and following RTQ-C [47, they are heated/cooled with equipment (unitary split system air-conditioning) that supply hot/cold air with an $11.0^{\circ} \mathrm{C}$ difference in relation to the zone's setpoint $\left(24.0^{\circ} \mathrm{C}\right.$ for cooling and $22.0^{\circ} \mathrm{C}$ for heating); the cooling and heating equipment's coefficient of performance are 3.28 and 3, respectively; and each equipment's fan has a $65 \%$ efficiency, $250 \mathrm{~Pa}$ static pressure and runs continuously. The corresponding heating/cooling 
availability schedules for each zone are equivalent to the lighting schedules defined for the respective zones (Fig. 6), as lighting is considered to be turned on during all working hours in these spaces.

\subsection{Climate location}

The weather data used in the dynamic simulation is the one available in the EnergyPlus weather data webpage for São Paulo, Brazil, and it is classified as a mild humid subtropical climate with hot summer and no dry season (Cfa type according to the Köppen classification [49]).

\section{Results and discussion}

The EPSAP algorithm ran a single time, which took a runtime of $1 \mathrm{~h}$ and $32 \mathrm{~min}$, using 20 threads in parallel computing in a ten-core $3.31 \mathrm{GHz}$ CPU machine with a $32 \mathrm{~GB}$ RAM, to produce six alternative building designs. The population size was 336 individuals. In the ES stage, there were 30 generations totalizing 19655 SHC iterations. Fig. 9 depicts the evolving indicators of the buildings' generation process and the weighted contribution of each activated penalty function. The new random individuals are inserted at each ES generation are noticeable by the peaks in the top graph (cost function $f$, Eq. A.8)), each followed by the corresponding SHC search stage, where the worst individual fitness, the population average fitness, and the display group average fitness indicators are represented. The bottom graphs show that the best individuals rapidly satisfy the penalty functions for boundary overflow $\left(f_{6}\right.$, Eq. A.19) $)$, elements overlap $\left(f_{7}\right.$ and $f_{13}$, Eq. A.20 and Eq. A.32, respectively), opening dimensions ( $f_{15}$, Eq. A.34), and indoor openings connectivity $\left(f_{18}\right.$, Eq. (A.37)). Therefore, the resulting designs are a consequence of the compromise between the penalty function compactness of clusters $\left(f_{5}\right.$, Eq. (A.18) $)$, circulation areas $\left(f_{9}\right.$, Eq. A.22 $)$, room dimensions $\left(f_{10}\right.$, Eq. A.23) $)$, room relative importance $\left(f_{12}\right.$, Eq. A.30), and opening accessibility $\left(f_{14}\right.$, Eq. A.33) $)$, which were not fully satisfied. The six individuals in the display group had a fitness ranging from 79.26 to 112.18. After completion of the generation procedure, the EnergyPlus IDF files are generated to assess the energy performance of the six buildings; they are publicly available on an open access server [50].

Fig. 10 depicts the 3D view of the generated buildings within the urban context. It is possible to observe that all the buildings satisfy the building boundary limits and adjacent buildings alignments that were specified. The buildings are also diverse in form, and openings have different orientations. The commercial spaces in the ground floor occupy freely the lot and satisfy the specified opening orientations of South or West. Regarding the apartments' performance, on the right side of each building view, the worst and the best energy performance stories are presented (only the residential 

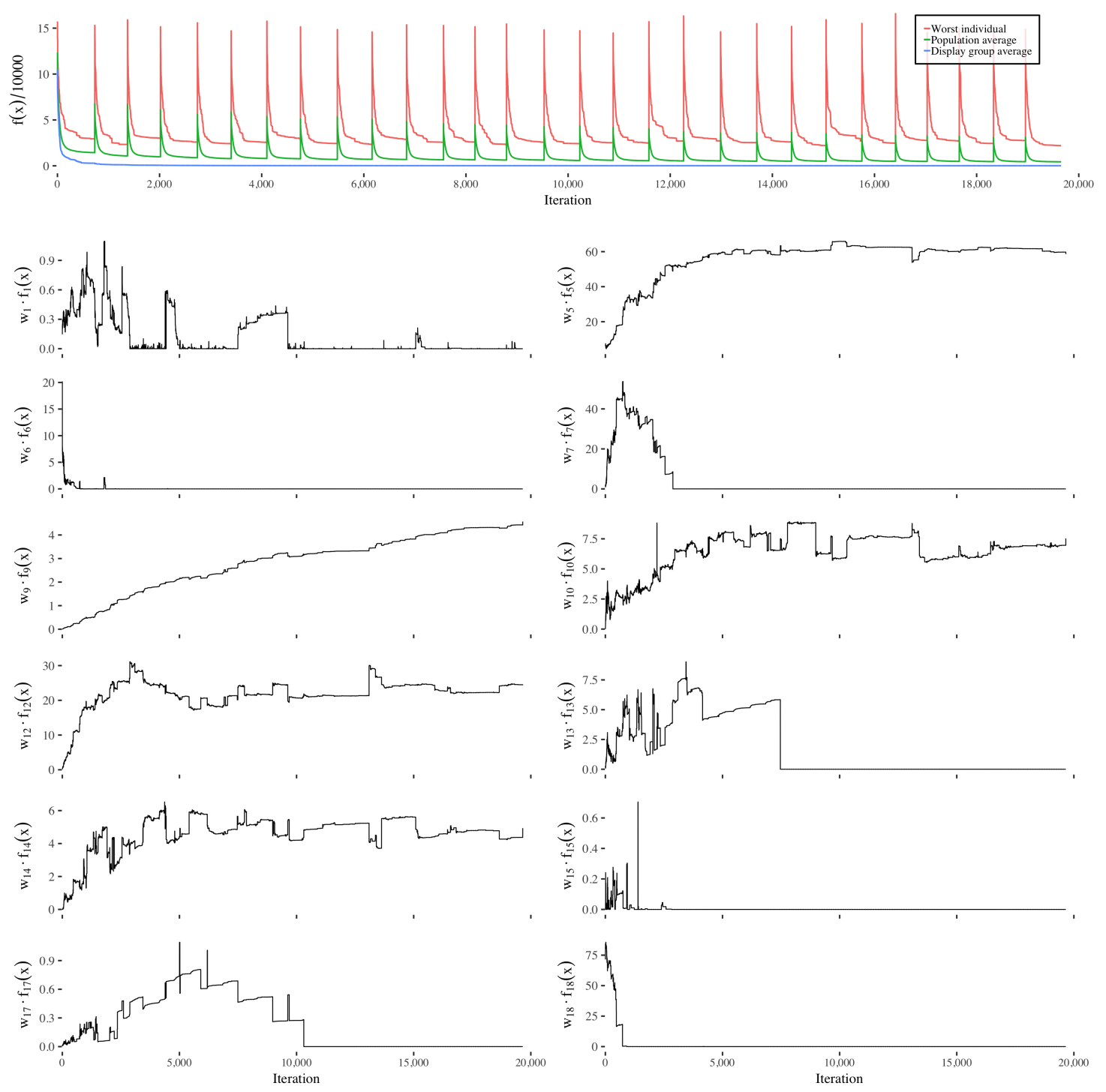

Fig. 9. Top graph depicts the evolving indicators of the generation process. The remaining graphs represent the penalty functions of the display group individuals average.

stories). The worst story - calculated by summing up the energy consumed by both apartments in all buildings is the first residential story $\left(L_{2}\right)$, while the story with the best energy performance is located at an intermediate story of the building: story $L_{9}$ in FPD 58, $L_{10}$ in FPD 149, $L_{8}$ in FPD 324, $L_{7}$ in FPD 163, $L_{6}$ in PFD 73, and, lastly, $L_{8}$ in FPD 319. Due to the combination of shadowing and reflection of solar radiation from the surrounding buildings and the adjacent stories' performance, the identified intermediate stories are the ones where the best balance between cooling and heating needs is found. The performance difference between stories in the same building ranges from $22 \%$ to $44 \%$ more energy consumption in comparison to the story with the best performance (FPD $5843 \%$, FPD $14944 \%$, FPD 324 29\%, FPD $16335 \%$, FPD $7322 \%$, and FPD $31939 \%$ ). However, these wide results are due to the high amount of energy consumed in the first residential story, as it can be clearly observed in Fig. 11, which depicts 
comparative graphs for the energy consumed for cooling and heating on every residential story for each apartment. The reason for the first residential story to have such high energy consumption in comparison to the remaining ones is that the former has higher surface area in contact with the outside air due to being suspended (ranging from $66 \%$ to $86 \%$ of suspended area; FPD $\mathbf{5 8} 76 \%$, FPD 149 84\%, FPD 324 86\%, FPD 163 85\%, FPD 73 66\%, and FPD $31976 \%$ ). Ignoring the outlier story having the worst performance, the energy consumption difference ranges from $9 \%$ to $12 \%$ (FPD $5812 \%$, FPD $14912 \%$, FPD 324 10\%, FPD $\mathbf{1 6 3} 9 \%$, FPD $\mathbf{7 3} 9 \%$, and FPD 319 11\%).

When stores are located directly under the apartments, such as, for example, Apartments T3 on story $L_{2}$ in buildings FPD 324, FPD 73, and FPD 319, the energy consumption for heating is similar to the ones placed on the upper stories (see Fig. 11). It is also possible to observe in Fig. 11 that all apartments in FPD 163 and FPD 73, and Apartment T3 in FPD 58, FPD 149, and FPD 319 have high heating needs and low cooling needs, while Apartment T3 in FPD 324 has high cooling needs. When comparing all buildings, the best story performance presents a difference of $11.7 \%$ between buildings ( $L_{7}$ in FPD 163 and $L_{10}$ in FPD 149).

In Fig. 10, the energy consumption for air-conditioning in each apartment is labeled with a colored gradient from green $\left(4 \mathrm{~kW} \cdot \mathrm{h} \cdot \mathrm{m}^{-2}\right)$ to red $\left(14 \mathrm{~kW} \cdot \mathrm{h} \cdot \mathrm{m}^{-2}\right)$. The building designs that have Apartment T2 facing West are the ones with the highest difference between stories (FPD 58, FPD 149, and FPD 319) and with Apartments T2 having the lowest heating needs. FPD 324 is the one that has the lowest heating demand and the highest cooling demand for Apartment T3, independently of the story level. As West-oriented facades are the least shadowed by the surroundings, the apartments facing that orientation are the ones with lowest heating energy consumption. The same is valid for Apartment T3 in FPD 73, albeit to a lesser extent, as it is placed Southwest, thus being partly self-shadowed during most of the day.

The smaller Apartments T2 have the lowest energy demand in all design solutions, regardless of the story on which they are located (see Tables 11 and 12). However, and due to the amount of energy consumed, it is Apartment T3 that defines the overall performance ranking of the building, except for FPD 324 and FPD 73.

Table 11. Apartments, vertical circulation, and commercial spaces floor areas.

\begin{tabular}{lrrrrrrrr}
\hline Building & Apart. T3 & Apart. T2 & Coffee H. & Office A & Office B & Shop & Stair & Elevator \\
\hline FPD 58 & $130.49 \mathrm{~m}^{2}$ & $109.88 \mathrm{~m}^{2}$ & $17.55 \mathrm{~m}^{2}$ & $33.62 \mathrm{~m}^{2}$ & $31.06 \mathrm{~m}^{2}$ & $20.94 \mathrm{~m}^{2}$ & $32.01 \mathrm{~m}^{2}$ & $3.29 \mathrm{~m}^{2}$ \\
FPD 149 & $146.71 \mathrm{~m}^{2}$ & $106.09 \mathrm{~m}^{2}$ & $20.71 \mathrm{~m}^{2}$ & $35.82 \mathrm{~m}^{2}$ & $24.25 \mathrm{~m}^{2}$ & $34.67 \mathrm{~m}^{2}$ & $25.74 \mathrm{~m}^{2}$ & $3.29 \mathrm{~m}^{2}$ \\
FPD 324 & $135.20 \mathrm{~m}^{2}$ & $102.08 \mathrm{~m}^{2}$ & $26.75 \mathrm{~m}^{2}$ & $17.14 \mathrm{~m}^{2}$ & $24.81 \mathrm{~m}^{2}$ & $18.67 \mathrm{~m}^{2}$ & $20.87 \mathrm{~m}^{2}$ & $3.80 \mathrm{~m}^{2}$ \\
FPD 163 & $155.56 \mathrm{~m}^{2}$ & $118.06 \mathrm{~m}^{2}$ & $22.99 \mathrm{~m}^{2}$ & $18.87 \mathrm{~m}^{2}$ & $17.18 \mathrm{~m}^{2}$ & $17.18 \mathrm{~m}^{2}$ & $34.00 \mathrm{~m}^{2}$ & $3.29 \mathrm{~m}^{2}$ \\
FPD 73 & $172.35 \mathrm{~m}^{2}$ & $149.96 \mathrm{~m}^{2}$ & $59.68 \mathrm{~m}^{2}$ & $19.98 \mathrm{~m}^{2}$ & $22.56 \mathrm{~m}^{2}$ & $31.27 \mathrm{~m}^{2}$ & $28.35 \mathrm{~m}^{2}$ & $4.39 \mathrm{~m}^{2}$ \\
FPD 319 & $146.26 \mathrm{~m}^{2}$ & $119.80 \mathrm{~m}^{2}$ & $29.43 \mathrm{~m}^{2}$ & $27.74 \mathrm{~m}^{2}$ & $31.48 \mathrm{~m}^{2}$ & $27.08 \mathrm{~m}^{2}$ & $28.80 \mathrm{~m}^{2}$ & $3.29 \mathrm{~m}^{2}$ \\
\hline
\end{tabular}



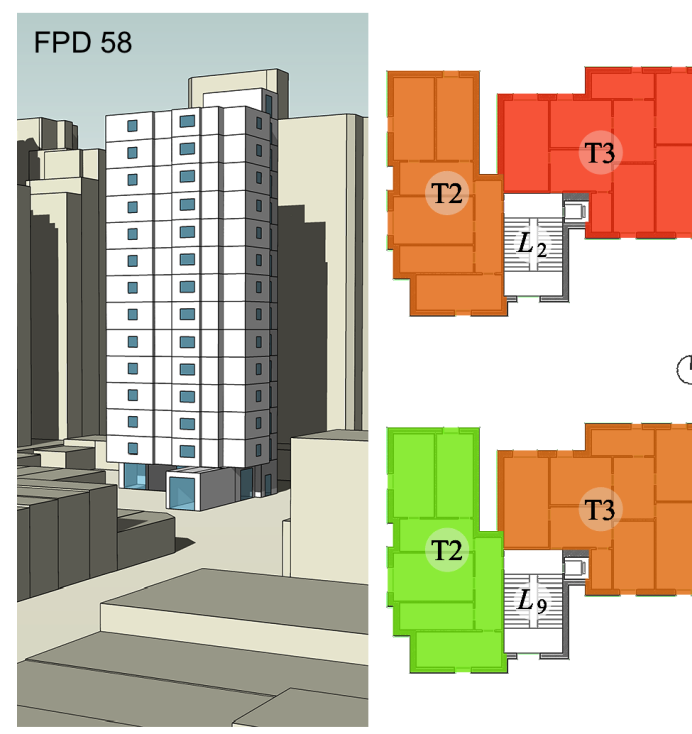

(1)

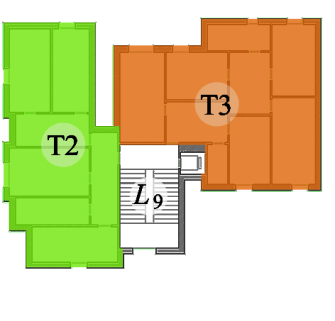

a)
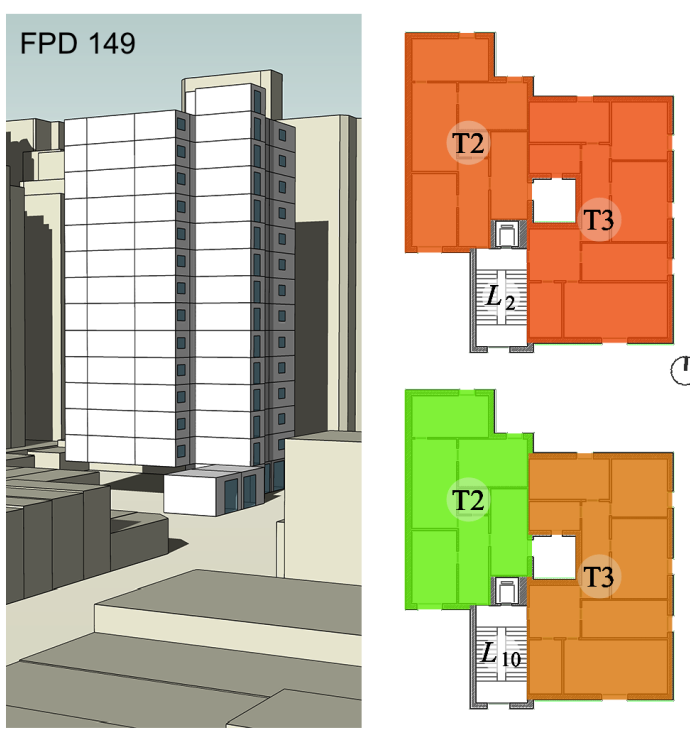

b)
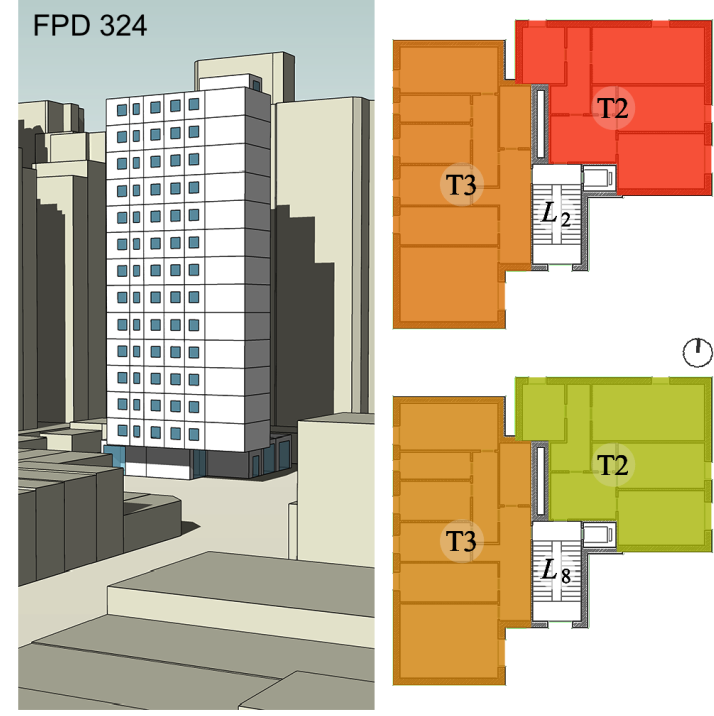

c)

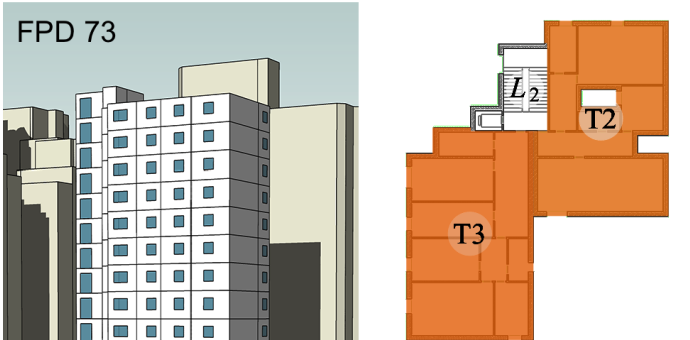

$(1)$
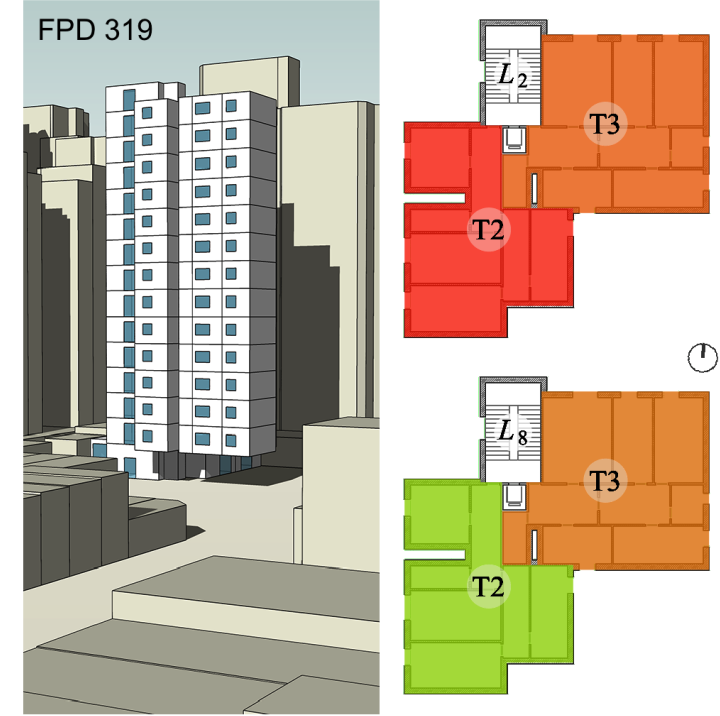

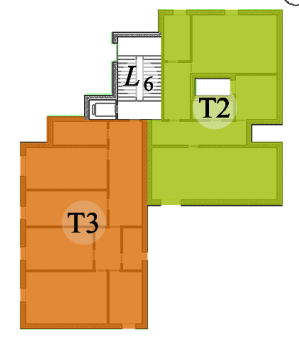

$\mathrm{kW} \cdot \mathrm{h} / \mathrm{m}^{2}$

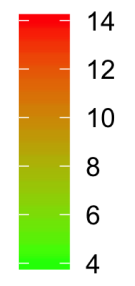

Fig. 10. The six generated buildings with the 3D simulation model perspective view on the left and two apartments' stories on the right. The top floor plan indicates the story with the worst energy performance, while the bottom one shows the story with the lowest energy consumption; the story number is marked over the stair space; the annual energy demand per floor area for air-conditioning is depicted by the colored gradient from green $\left(4 \mathrm{~kW} \cdot \mathrm{h} \cdot \mathrm{m}^{-2}\right)$ to red $\left(14 \mathrm{~kW} \cdot \mathrm{h} \cdot \mathrm{m}^{-2}\right)$. Floor plans are not in scale. 
FPD 58

Apartment T3

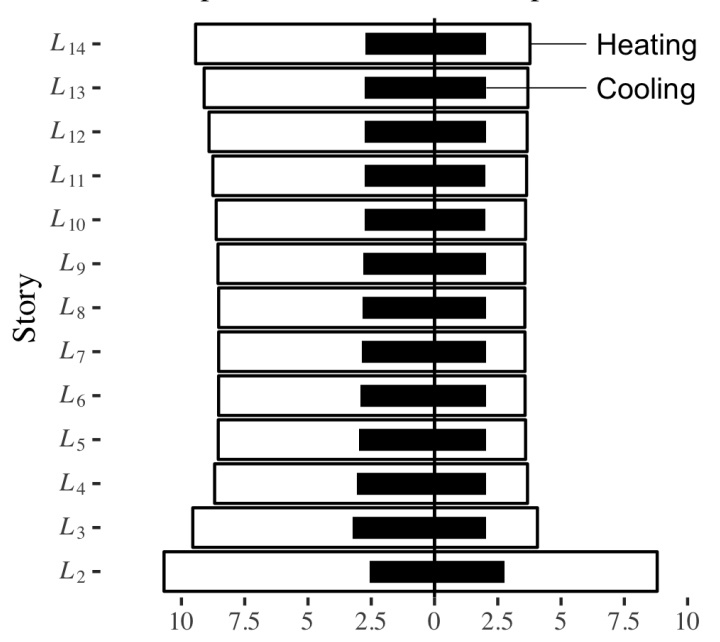

N
FPD 149

Apartment T3

Apartment T2

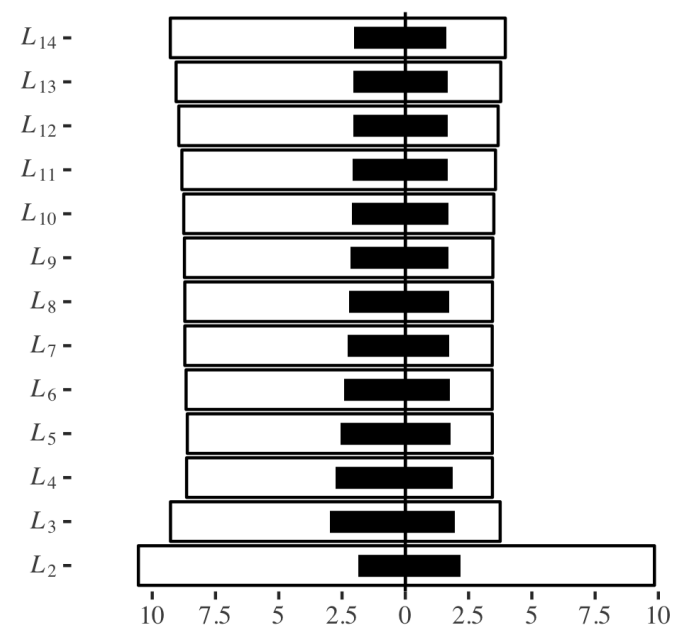

FPD 73

Apartment T3 Apartment T2

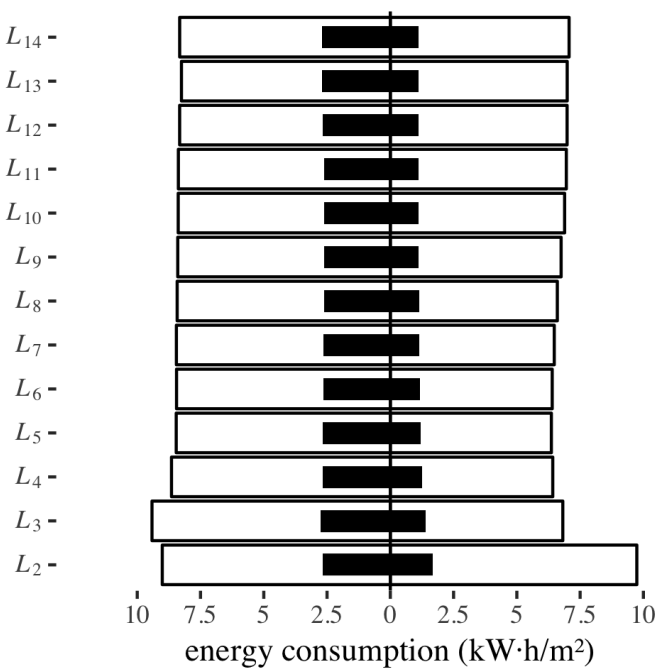

FPD 324

Apartment T3 Apartment T2

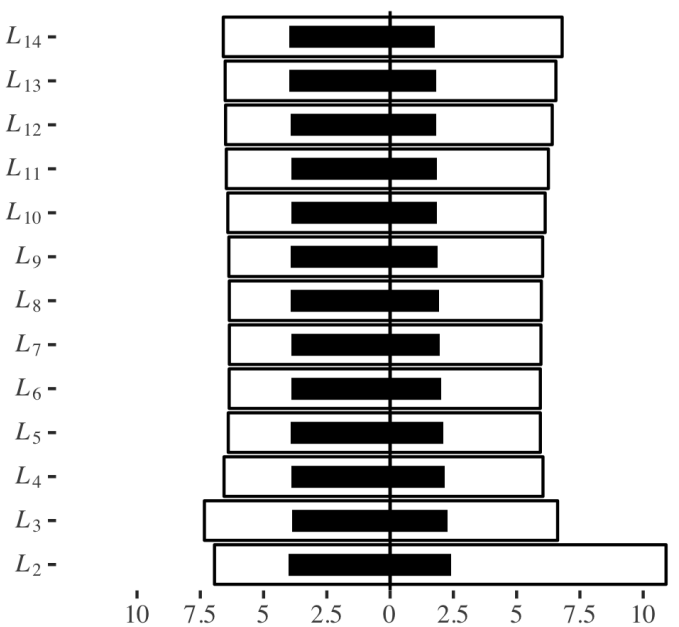

FPD 319

Apartment T3 Apartment T2

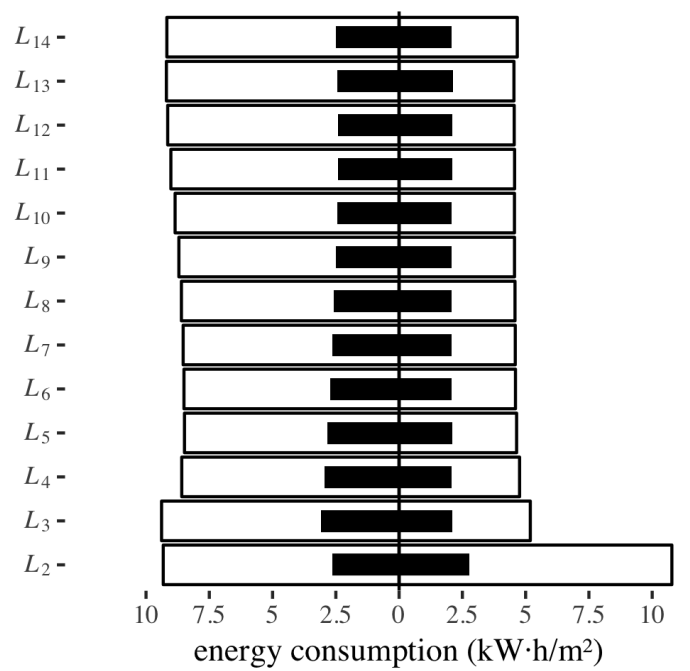

Fig. 11. Apartments' heating and cooling energy consumption per residential story $\left(L_{2}\right.$ to $\left.L_{L 14}\right)$. The cooling energy is marked as black bar while the heating energy is marked as white bar. 
Table 12. Annual total energy, cooling energy, and heating energy consumption for air-conditioning per floor area. Story and apartment lowest energy consumption are marked in bold font for each building.

\begin{tabular}{|c|c|c|c|c|c|c|c|c|c|c|c|c|c|c|c|}
\hline \multirow[b]{3}{*}{ Story } & \multicolumn{5}{|c|}{ FPD $58\left(\mathrm{~kW} \cdot \mathrm{h} \cdot \mathrm{m}^{-2}\right)$} & \multicolumn{5}{|c|}{ FPD $149\left(\mathrm{~kW} \cdot \mathrm{h} \cdot \mathrm{m}^{-2}\right)$} & \multicolumn{5}{|c|}{ FPD $324\left(\mathrm{~kW} \cdot \mathrm{h} \cdot \mathrm{m}^{-2}\right)$} \\
\hline & \multicolumn{2}{|c|}{ Apartment T3 } & \multicolumn{2}{|c|}{ Apartment T2 } & \multirow[b]{2}{*}{ Total } & \multicolumn{2}{|c|}{ Apartment T3 } & \multicolumn{2}{|c|}{ Apartment T2 } & \multirow[b]{2}{*}{ Total } & \multicolumn{2}{|c|}{ Apartment T3 } & \multicolumn{2}{|c|}{ Apartment T2 } & \multirow[b]{2}{*}{ Total } \\
\hline & Heating & Cooling & Heating & Cooling & & Heating & Cooling & Heating & Cooling & & Heating & Cooling & Heating & Cooling & \\
\hline$L_{1}$ & - & - & - & - & 104.330 & - & - & - & - & 89.137 & - & - & - & - & 118.703 \\
\hline$L_{2}$ & 10.689 & 2.570 & 8.799 & 2.753 & 12.478 & 10.547 & 1.864 & 9.844 & 2.186 & 12.250 & 6.939 & 4.015 & 10.904 & 2.419 & 11.973 \\
\hline$L_{3}$ & 9.552 & 3.248 & 4.066 & 2.045 & 9.742 & 9.278 & 2.979 & 3.748 & 1.970 & 9.513 & 7.338 & 3.885 & 6.619 & 2.273 & 10.220 \\
\hline$L_{4}$ & 8.689 & 3.073 & 3.674 & 2.027 & 8.991 & 8.642 & 2.743 & 3.441 & 1.862 & 8.833 & 6.562 & 3.889 & 6.041 & 2.162 & 9.484 \\
\hline$L_{5}$ & 8.546 & 2.979 & 3.598 & 2.031 & 8.830 & 8.614 & 2.559 & 3.437 & 1.789 & 8.676 & 6.395 & 3.918 & 5.937 & 2.090 & 9.329 \\
\hline$L_{6}$ & 8.532 & 2.921 & 3.578 & 2.028 & 8.779 & 8.663 & 2.408 & 3.433 & 1.752 & 8.601 & 6.359 & 3.914 & 5.936 & 2.025 & 9.278 \\
\hline$L_{7}$ & 8.529 & 2.884 & 3.574 & 2.029 & 8.757 & 8.712 & 2.292 & 3.434 & 1.732 & 8.553 & 6.352 & 3.911 & 5.961 & 1.969 & 9.260 \\
\hline$L_{8}$ & 8.529 & 2.852 & 3.570 & 2.031 & 8.739 & 8.712 & 2.218 & 3.443 & 1.720 & 8.510 & 6.354 & 3.925 & 5.976 & 1.926 & 9.257 \\
\hline$L_{9}$ & 8.557 & 2.809 & 3.573 & 2.034 & 8.734 & 8.728 & 2.159 & 3.460 & 1.706 & 8.487 & 6.371 & 3.935 & 6.028 & 1.890 & 9.278 \\
\hline$L_{10}$ & 8.627 & 2.771 & 3.598 & 2.019 & 8.755 & 8.755 & 2.113 & 3.498 & 1.691 & 8.485 & 6.413 & 3.902 & 6.127 & 1.859 & 9.312 \\
\hline$L_{11}$ & 8.759 & 2.756 & 3.639 & 2.011 & 8.834 & 8.828 & 2.084 & 3.564 & 1.687 & 8.536 & 6.472 & 3.887 & 6.255 & 1.839 & 9.384 \\
\hline$L_{12}$ & 8.910 & 2.766 & 3.660 & 2.028 & 8.939 & 8.951 & 2.063 & 3.668 & 1.686 & 8.638 & 6.501 & 3.925 & 6.406 & 1.834 & 9.485 \\
\hline$L_{13}$ & 9.103 & 2.773 & 3.689 & 2.049 & 9.069 & 9.058 & 2.049 & 3.772 & 1.666 & 8.728 & 6.518 & 3.973 & 6.552 & 1.817 & 9.578 \\
\hline$L_{14}$ & 9.441 & 2.729 & 3.772 & 2.029 & 9.259 & 9.286 & 2.016 & 3.951 & 1.616 & 8.895 & 6.592 & 3.978 & 6.797 & 1.761 & 9.704 \\
\hline \multirow[t]{3}{*}{ Total } & 116.464 & 37.129 & 52.788 & 27.115 & 164.687 & 116.775 & 29.544 & 52.693 & 23.063 & 157.414 & 85.166 & 51.056 & 85.536 & 25.863 & 169.251 \\
\hline & \multicolumn{5}{|c|}{ FPD $163\left(\mathrm{~kW} \cdot \mathrm{h} \cdot \mathrm{m}^{-2}\right)$} & \multicolumn{5}{|c|}{ FPD $73\left(\mathrm{~kW} \cdot \mathrm{h} \cdot \mathrm{m}^{-2}\right)$} & \multicolumn{5}{|c|}{ FPD $319\left(\mathrm{~kW} \cdot \mathrm{h} \cdot \mathrm{m}^{-2}\right)$} \\
\hline & \multicolumn{2}{|c|}{ Apartment T3 } & \multicolumn{2}{|c|}{ Apartment T2 } & \multirow[b]{2}{*}{ Total } & \multicolumn{2}{|c|}{ Apartment T3 } & \multicolumn{2}{|c|}{ Apartment T2 } & \multirow[b]{2}{*}{ Total } & Apartn & ent $\mathbf{T 3}$ & Apartn & ent $\mathbf{T 2}$ & \\
\hline Story & Heating & Cooling & Heating & Cooling & & Heating & Cooling & Heating & Cooling & & Heating & Cooling & Heating & Cooling & Total \\
\hline$L_{1}$ & - & - & - & - & 134.579 & - & - & - & - & 66.648 & - & - & - & - & 84.129 \\
\hline$L_{2}$ & 10.189 & 2.195 & 11.258 & 1.987 & 12.755 & 9.011 & 2.664 & 9.741 & 1.688 & 11.560 & 9.320 & 2.630 & 10.778 & 2.764 & 12.666 \\
\hline$L_{3}$ & 9.692 & 2.867 & 5.572 & 1.846 & 10.341 & 9.417 & 2.743 & 6.816 & 1.390 & 10.321 & 9.386 & 3.096 & 5.184 & 2.096 & 10.140 \\
\hline$L_{4}$ & 9.049 & 2.674 & 5.305 & 1.741 & 9.705 & 8.646 & 2.659 & 6.419 & 1.253 & 9.615 & 8.589 & 2.950 & 4.760 & 2.071 & 9.419 \\
\hline$L_{5}$ & 8.955 & 2.538 & 5.323 & 1.683 & 9.557 & 8.460 & 2.662 & 6.364 & 1.193 & 9.463 & 8.481 & 2.830 & 4.643 & 2.090 & 9.250 \\
\hline$L_{6}$ & 8.974 & 2.431 & 5.374 & 1.623 & 9.504 & 8.447 & 2.650 & 6.397 & 1.162 & 9.451 & 8.501 & 2.731 & 4.598 & 2.087 & 9.184 \\
\hline$L_{7}$ & 9.014 & 2.356 & 5.411 & 1.581 & 9.481 & 8.453 & 2.629 & 6.478 & 1.148 & 9.474 & 8.533 & 2.647 & 4.590 & 2.077 & 9.148 \\
\hline$L_{8}$ & 9.085 & 2.305 & 5.430 & 1.553 & 9.489 & 8.422 & 2.626 & 6.599 & 1.136 & 9.507 & 8.602 & 2.569 & 4.579 & 2.079 & 9.140 \\
\hline$L_{9}$ & 9.218 & 2.260 & 5.442 & 1.530 & 9.534 & 8.399 & 2.628 & 6.749 & 1.127 & 9.561 & 8.702 & 2.500 & 4.560 & 2.085 & 9.150 \\
\hline$L_{10}$ & 9.364 & 2.218 & 5.435 & 1.509 & 9.581 & 8.381 & 2.621 & 6.887 & 1.124 & 9.610 & 8.852 & 2.444 & 4.558 & 2.087 & 9.202 \\
\hline$L_{11}$ & 9.480 & 2.192 & 5.410 & 1.503 & 9.619 & 8.375 & 2.624 & 6.955 & 1.128 & 9.642 & 9.018 & 2.417 & 4.563 & 2.088 & 9.281 \\
\hline$L_{12}$ & 9.546 & 2.180 & 5.385 & 1.505 & 9.639 & 8.324 & 2.661 & 6.985 & 1.126 & 9.647 & 9.144 & 2.416 & 4.548 & 2.112 & 9.354 \\
\hline$L_{13}$ & 9.579 & 2.174 & 5.374 & 1.499 & 9.647 & 8.253 & 2.701 & 6.989 & 1.125 & 9.633 & 9.195 & 2.433 & 4.538 & 2.131 & 9.396 \\
\hline$L_{14}$ & 9.679 & 2.165 & 5.486 & 1.456 & 9.729 & 8.323 & 2.699 & 7.064 & 1.114 & 9.698 & 9.177 & 2.489 & 4.669 & 2.079 & 9.451 \\
\hline Total & 121.823 & 30.557 & 76.206 & 21.016 & 166.069 & 110.912 & 34.566 & 90.441 & 15.713 & 154.785 & 115.501 & 34.152 & 66.568 & 27.846 & 161.375 \\
\hline
\end{tabular}


If ranked according to the story annual energy consumption, the building design FPD 58 has the lowest energy consumption with $2099.3 \mathrm{~kW} \cdot \mathrm{h}$, followed by FPD $1492144.9 \mathrm{~kW} \cdot \mathrm{h}$, FPD $3242196.4 \mathrm{~kW} \cdot \mathrm{h}$, FPD $3192431.8 \mathrm{~kW} \cdot \mathrm{h}$, FPD $1632594.2 \mathrm{~kW} \cdot \mathrm{h}$, and lastly, FPD 73 $3046.1 \mathrm{~kW} \cdot \mathrm{h}$. However, when ranking the building designs by story total energy consumption per floor area, FPD 149 presents the best design with $8.485 \mathrm{~kW} \cdot \mathrm{h} \cdot \mathrm{m}^{-2}$, followed by $\mathbf{F P D} \mathbf{5 8}$ $8.734 \mathrm{~kW} \cdot \mathrm{h} \cdot \mathrm{m}^{-2}$, FPD $3199.140 \mathrm{~kW} \cdot \mathrm{h} \cdot \mathrm{m}^{-2}$, FPD $3249.257 \mathrm{~kW} \cdot \mathrm{h} \cdot \mathrm{m}^{-2}$, FPD $739.451 \mathrm{~kW} \cdot \mathrm{h} \cdot \mathrm{m}^{-2}$, and FPD $1639.481 \mathrm{~kW} \cdot \mathrm{h} \cdot \mathrm{m}^{-2}$ (see Table 12 ).

\section{Conclusion}

Automated floor plan design generation methods usually ignore the urban context in their generation and performance evaluation. The approach presented in this paper includes the urban surroundings to limit the building lot, to define the building boundary, to prevent inadequate openings orientation, and to define building alignments with adjacent buildings. Besides including urban elements (adjacent buildings, vegetation, and terrain) during the buildings' generation phase, these are also considered during the performance assessment using dynamic simulation.

The energy performance simulation of new buildings is important to help building design practitioners take informed decisions and implement energy efficiency measures. For this reason, accurate models are necessary to increase the trustworthiness of the results. As shown by the results, the urban context affects the building design solutions in their geometry (satisfying construction areas, building boundaries, urban alignments, relative and absolute position of spaces and openings, and openings orientations) and in their performance (the impact of shadowing and reflection of solar radiation from the surrounding buildings). With the inclusion of surrounding buildings, vegetation, and terrain, both the generative design methods and simulation models increase the computational burden, which is the most cumbersome problem. The use of metadata associated to each building, or group of buildings, allows to reduce such burden.

The results demonstrated that the EPSAP algorithm was able to produce distinctive and alternative solutions for this high-rise urban building scenario. The results also showed that either the buildings' performance or the story and apartment performance (despite stories having equal geometry and construction) vary significantly, with intermediate stories having the best energy performance. Also, the size and position of each apartment (and also the window orientation) have a strong impact in the building performance. The best story performance difference between buildings can reach $11.7 \%$ of energy consumption per floor area. The results also illustrated that the energy consumption for air-conditioning between stories in the same building ranges from $9 \%$ 
to $12 \%$ relatively to the best performing one (ignoring the first story, which is an outlier; otherwise the difference would range from $22 \%$ to $44 \%$ ). Therefore, this approach can be a useful tool for building designers to explore and test solutions in fast prototyping tasks of early design stages.

This new approach is originally intended to have a set of urban and building requirements and preferences in a single automated tool. Its uniqueness is also a contribution to fast prototyping of buildings, not only in building design scenarios, but also as a research tool to produce datasets of building designs for the statistical analysis of specific building phenomena. Despite the demonstrated capabilities of the presented approach, future developments and tests are required. Some of the developments are the inclusion of alternative requirements (e.g., alignment with building A or alignment with building B), occupation of underground levels, definition of walkthroughs in the urban lot, etc., and testing in denser urban environments and in renovation scenarios. Additionally, a methodology to consider the interactions of the generated building with the micro urban climate to improve the indoor thermal performance of the building will also be implemented.

\section{Data availability}

The dataset related to the six IDF files of 15-story buildings in São Paulo can be found at URL https://bit.ly/2F2QY0y, hosted at figshare ([50]).

\section{Acknowledgments}

The research presented has been developed under the Energy for Sustainability Initiative of the University of Coimbra (UC).

Funding: This work has been financed by the Portuguese Foundation for Science and Technology (FCT) and by the European Regional Development Fund (FEDER) through COMPETE 2020 Operational Program for Competitiveness and Internationalization (POCI) in the framework of the research project Ren4EEnIEQ (PTDC/EMS-ENE/3238/2014, POCI-01-0145-FEDER-016760, and LISBOA-01-0145-FEDER-016760) and by project UID/Multi/00308/2019 supported by FCT.

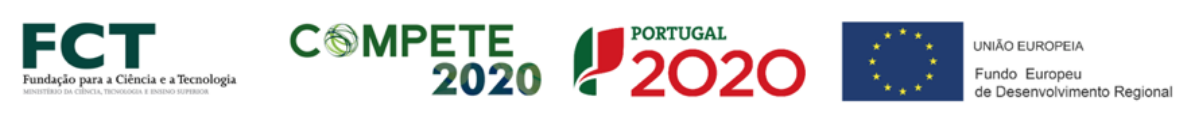

Declarations of interest: none. 


\section{References}

[1] Soares, N., Martins, A., Carvalho, A., Caldeira, C., Du, C., Castanheira, É., et al. The challenging paradigm of interrelated energy systems towards a more sustainable future. Renewable and Sustainable Energy Reviews 2018;95:171-193. doi $10.1016 /$ j.rser.2018.07.023.

[2] Pacheco, R., Ordóñez, J., Martínez, G.. Energy efficient design of building: A review. Renewable and Sustainable Energy Reviews 2012;16(6):3559-3573. doi 10.1016/j.rser.2012.03.045.

[3] Mirrahimi, S., Mohamed, M.F., Haw, L.C., Ibrahim, N.L.N., Yusoff, W.F.M., Aflaki, A.. The effect of building envelope on the thermal comfort and energy saving for high-rise buildings in hot-humid climate. Renewable and Sustainable Energy Reviews 2016;53:1508-1519. doi $10.1016 /$ j.rser.2015.09.055.

[4] Stevanović, S.. Optimization of passive solar design strategies: A review. Renewable and Sustainable Energy Reviews 2013;25:177-196. doi 10.1016/j.rser.2013.04.028

[5] Machairas, V., Tsangrassoulis, A., Axarli, K.. Algorithms for optimization of building design: A review. Renewable and Sustainable Energy Reviews 2014;31(1364):101-112. doi 10.1016/j.rser.2013.11.036

[6] Yu, W., Li, B., Jia, H., Zhang, M., Wang, D.. Application of multi-objective genetic algorithm to optimize energy efficiency and thermal comfort in building design. Energy and Buildings 2015;88(5):135-143. doi $10.1016 /$ j.enbuild.2014.11.063.

[7] Hamdy, M., Nguyen, A.T., Hensen, J.L.. A performance comparison of multi-objective optimization algorithms for solving nearly-zero-energy-building design problems. Energy and Buildings 2016;121:57-71. doi 10.1016/j. enbuild.2016.03.035.

[8] Amaral, A.R., Rodrigues, E., Rodrigues Gaspar, A., Gomes, Á.. Review on performance aspects of nearly zero-energy districts. Sustainable Cities and Society 2018;43:406-420. doi $10.1016 /$ j.scs.2018.08.039.

[9] He, J., Hoyano, A., Asawa, T.. A numerical simulation tool for predicting the impact of outdoor thermal environment on building energy performance. Applied Energy 2009;86(9):1596-1605. doi 10.1016/j.apenergy. 2008.12 .034

[10] Oxman, R.. Performance-Based Design: Current Practices and Research Issues. International Journal of Architectural Computing 2008;6(1):1-17. doi 10.1260/147807708784640090.

[11] Oxman, R.. Performative design: A performance-based model of digital architectural design. Environment and Planning B: Planning and Design 2009;36(6):1026-1037. doi 10.1068/b34149.

[12] Shea, K., Aish, R., Gourtovaia, M.. Towards integrated performance-driven generative design tools. Automation in Construction 2005;14(2 SPEC. ISS.):253-264. doi 10.1016/j . autcon.2004.07.002

[13] Kolarevic, B., editor. Architecture in the Digital Age: Design and Manufacturing. New York: Spon Press; 2009. ISBN 0-203-63777-1.

[14] Chakrabarti, A., Shea, K., Stone, R., Cagan, J., Campbell, M., Hernandez, N.V., et al. ComputerBased Design Synthesis Research: An Overview. Journal of Computing and Information Science in Engineering 2011;11(2):021003. doi 10.1115/1.3593409.

[15] Kolarevic, B., Malkawi, A.M., editors. Performative Architecture: Beyond Instrumentality. New York: Spon Press; 2005. ISBN 0-415-70083-3.

[16] Turrin, M., Von Buelow, P., Stouffs, R.. Design explorations of performance driven geometry in architectural design using parametric modeling and genetic algorithms. Advanced Engineering Informatics 2011;25(4):656675. doi $10.1016 / \mathrm{j}$.aei.2011.07.009. 
[17] Ercan, B., Elias-Ozkan, S.T.. Performance-based parametric design explorations: A method for generating appropriate building components. Design Studies 2015;38:33-53. doi 10.1016/j.destud.2015.01.001.

[18] Santos, L., Schleicher, S., Caldas, L.. Automation of CAD models to BEM models for performance based goaloriented design methods. Building and Environment 2017;112:144-158. doi 10.1016/j.buildenv.2016.10.015.

[19] Ekici, B., Cubukcuoglu, C., Turrin, M., Sariyildiz, I.S.. Performative computational architecture using swarm and evolutionary optimisation: A review. Building and Environment 2019;147(October 2018):356-371. doi $10.1016 /$ j.buildenv.2018.10.023

[20] Han, Y., Taylor, J.E., Pisello, A.L.. Exploring mutual shading and mutual reflection inter-building effects on building energy performance. Applied Energy 2017;185:1556-1564. doi 10.1016/j .apenergy .2015.10.170

[21] Koenig, R., Schneider, S.. Hierarchical structuring of layout problems in an interactive evolutionary layout system. Artificial Intelligence for Engineering Design, Analysis and Manufacturing 2012;26(02):129-142. doi:10. $1017 / \mathrm{S} 0890060412000030$

[22] Dino, I.G.. An evolutionary approach for 3D architectural space layout design exploration. Automation in Construction 2016;69:131-150. doi $10.1016 / \mathrm{j}$. autcon.2016.05.020.

[23] Dino, I.G., Üçoluk, G.. Multiobjective Design Optimization of Building Space Layout, Energy, and Daylighting Performance. Journal of Computing in Civil Engineering 2017;31(5):04017025. URL: http://ascelibrary.org/ doi/10.1061/\{\%\}28ASCE\{\%\}29CP. 1943-5487.0000669, doi 10.1061/(ASCE) CP. 1943-5487.0000669.

[24] Wang, X.Y., Yang, Y., Zhang, K.. Customization and generation of floor plans based on graph transformations. Automation in Construction 2018;94:405-416. doi 10.1016/j . autcon.2018.07.017

[25] Duarte, J.P.. A discursive grammar for customizing mass housing: the case of Siza's houses at Malagueira. Automation in Construction 2005;14(2):265-275. doi $10.1016 / \mathrm{j}$. autcon.2004.07.013.

[26] Hou, D., Stouffs, R.. An algorithmic design grammar for problem solving. Automation in Construction 2018;94:417-437. doi $10.1016 / \mathrm{j}$. autcon.2018.07.013

[27] Rodrigues, E., Amaral, A.R., Gaspar, A.R., Gomes, Á.. An Approach to Urban Quarter Design Using Building Generative Design and Thermal Performance Optimization. Energy Procedia 2015;78:2899-2904. doi 10.1016/ j.egypro.2015.11.662

[28] Rodrigues, E., Soares, N., Fernandes, M.S., Gaspar, A.R., Gomes, Á., Costa, J.J.. An integrated energy performance-driven generative design methodology to foster modular lightweight steel framed dwellings in hot climates. Energy for Sustainable Development 2018;44:21-36. doi 10.1016/j.esd.2018.02.006.

[29] Hua, H., Hovestadt, L., Tang, P., Li, B.. Integer programming for urban design. European Journal of Operational Research 2019;274(3):1125-1137. doi $10.1016 /$ j.ejor.2018.10.055

[30] Nault, E., Waibel, C., Carmeliet, J., Andersen, M.. Development and test application of the UrbanSOLve decision-support prototype for early-stage neighborhood design. Building and Environment 2018;137(February):58-72. doi 10.1016/j.buildenv.2018.03.033.

[31] Granadeiro, V., Correia, J.R., Leal, V.M., Duarte, J.P.. Envelope-related energy demand: A design indicator of energy performance for residential buildings in early design stages. Energy and Buildings 2013;61:215-223. doi $10.1016 / j . e n b u i l d .2013 .02 .018$

[32] Rodrigues, E., Amaral, A.R., Gaspar, A.R., Gomes, Á.. How reliable are geometry-based building indices as thermal performance indicators? Energy Conversion and Management 2015;101:561-578. doi 10.1016/j . enconman.2015.06.011 
[33] Rodrigues, E., Fernandes, M.S., Soares, N., Gomes, Á., Gaspar, A.R., Costa, J.J.. The potential impact of low thermal transmittance construction on the European design guidelines of residential buildings. Energy and Buildings 2018;178:379-390. doi 10.1016/j.enbuild.2018.08.009

[34] Fernandes, M.S., Rodrigues, E., Gaspar, A.R., Costa, J.J., Gomes, Á.. The impact of thermal transmittance variation on building design in the Mediterranean region. Applied Energy 2019;239:581-597. doi 10.1016/j. apenergy.2019.01.239

[35] Rodrigues, E., Fernandes, M.S., Gaspar, A.R., Gomes, Á., Costa, J.J.. Thermal transmittance effect on energy consumption of mediterranean buildings with different thermal mass. Applied Energy 2019; In Press. doi $10.1016 / \mathrm{j}$. apenergy .2019.113437

[36] Loonen, R.C.G.M., de Klijn-Chevalerias, M.L., Hensen, J.L.M.. Opportunities and pitfalls of using building performance simulation in explorative R\&D contexts. Journal of Building Performance Simulation 2019;:117 doi $10.1080 / 19401493.2018 .1561754$.

[37] Frayssinet, L., Merlier, L., Kuznik, F., Hubert, J.L., Milliez, M., Roux, J.J.. Modeling the heating and cooling energy demand of urban buildings at city scale. Renewable and Sustainable Energy Reviews 2018;81:2318-2327. doi $10.1016 /$ j.rser.2017.06.040

[38] Open street map. 2018. URL: http://openstreetmap.org.

[39] Rodrigues, E., Gaspar, A.R., Gomes, Á.. An evolutionary strategy enhanced with a local search technique for the space allocation problem in architecture, Part 1: Methodology. Computer-Aided Design 2013;45(5):887-897. doi $10.1016 / \mathrm{j} \cdot \mathrm{cad} .2013 .01 .001$.

[40] Rodrigues, E., Gaspar, A.R., Gomes, Á.. An evolutionary strategy enhanced with a local search technique for the space allocation problem in architecture, Part 2: Validation and performance tests. Computer-Aided Design 2013;45(5):898-910. doi 10.1016/j.cad.2013.01.003.

[41] Rodrigues, E., Gaspar, A.R., Gomes, Á.. An approach to the multi-level space allocation problem in architecture using a hybrid evolutionary technique. Automation in Construction 2013;35:482-498. doi 10.1016/ j.autcon.2013.06.005

[42] Rodrigues, E., Gaspar, A.R., Gomes, Á.. Automated approach for design generation and thermal assessment of alternative floor plans. Energy and Buildings 2014;81:170-181. doi $10.1016 / \mathrm{j}$.enbuild.2014.06.016

[43] Rodrigues, E., Gaspar, A.R., Gomes, Á.. Improving thermal performance of automatically generated floor plans using a geometric variable sequential optimization procedure. Applied Energy 2014;132:200-215. doi:10. 1016/j.apenergy.2014.06.068

[44] Energyplus version 8.9 documentation: Input output reference manual. Tech. Rep.; U.S. Department of Energy; 2018. URL: https://energyplus.net

[45] Leitzke, R.K., da Silva, O.M., da Cunha, E.G., da Silva, A.C.B.. Otimização de dispositivos de proteção solar com base em simulação computacional: Uso da ferramenta EMS do EnergyPlus. In: XIV ENCAC - Encontro Nacional de Conforto no Ambiente Construído, X ELACAC - Encontro Latino-Americano de Conforto no Ambiente Construído. 2017, p. 1378-1387.

[46] Regulamento técnico da qualidade para o nível de eficiência energética de edificações residenciais (rtq-r). Tech. Rep.; Ministério do Desenvolvimento, Indústria e Comércio Exterior; 2012.

[47] Regulamento técnico da qualidade para o nível de eficiência energética de edificações comerciais, de serviços e públicas (rtq-c). Tech. Rep.; Ministério do Desenvolvimento, Indústria e Comércio Exterior; 2010. 
[48] 2013 ashrae handbook: Fundamentals. Tech. Rep.; American Society of Heating, Refrigerating and AirConditioning Engineers; 2013.

[49] Kottek, M., Grieser, J., Beck, C., Rudolf, B., Rubel, F.. World Map of the Köppen-Geiger climate classification updated. Meteorologische Zeitschrift 2006;15(3):259-263. doi 10.1127/0941-2948/2006/0130.

[50] Rodrigues, E., Fernandes, M., Gaspar, A.R., Gomes, Á., Costa, J.J.. Dataset of six IDF files of 15-story buildings with urban context from São Paulo Brazil. 2018. URL: https://bit.1y/2F2QY0y, doi 10.6084/m9. figshare.6957401.

\section{Appendix A. Mathematical Model}

The population size $\left(N_{p}\right)$ is computed according to Eq. A.1, and it is a function of the number of objects to be allocated. The number of spaces $\left(N_{s}\right)$, interior openings $\left(N_{i o}\right)$, and exterior openings $\left(N_{e o}\right)$ in the floor plan design are summed up and multiplied by the number of individuals to be screened $\left(N_{d g}\right)$. Finally, a factor $k$, set by the user, is used to adjust the population size when necessary.

$$
N_{p}=k \cdot N_{d g} \cdot\left(N_{s}+N_{i o}+N_{e o}\right)
$$

Each individual chromosome is coded as a vector of real and natural numbers that define a set of objects in a cascade manner. The individual $\left(I_{i}\right.$, Eq. A.2) has an entrance story elevation (ie), a north angle deviation $(\mathrm{in})$, a set of stories $(L)$, a set of spaces $(S)$, and a set of interior openings $(\mathrm{Oi})$.

$$
\begin{aligned}
I_{i}\left\{i e, i n,\left\{L_{1}, \cdots, L_{n}\right\},\left\{S_{1}, \cdots, S_{n}\right\},\left\{O i_{1}, \cdots, O i_{n}\right\}\right\} ; & 1 \leqslant i \leqslant N_{p}, \\
& \text { ie } \in \mathbb{R}, \\
& \text { in } \in \mathbb{R} \wedge-45<\text { in }<45
\end{aligned}
$$

The story object $\left(L_{j}\right.$, Eq. A.3 $)$ is defined by its type $(l t, 0$ for the underground level, 1 for the ground floor level, and 2 for the upper level), and the story height $(l h)$, which is the difference between the floor level of the current story and the floor level of the upper story.

$$
\begin{aligned}
L_{j}\{l t, l h\} ; & 1 \leqslant j \leqslant N_{s t}, \\
& l t \in \mathbb{N}_{3}, \\
& l h \in \mathbb{R}, 0<l h
\end{aligned}
$$

Each space $\left(S_{k}\right.$, Eq. A.4) can be a negative space (e.g., a building yard), room, stair, or an elevator $(s t=\{0,1,2,3\}$, respectively). The space also comprises a set of floors $(F)$, which correspond to the room pavement, a set of exterior openings $(O e)$, the lower story number $(l s)$, 
and the upper story number (us) that this space serves.

$$
\begin{aligned}
S_{k}\left\{s t,\left\{F_{1}, \cdots, F_{n}\right\},\left\{O e_{1}, \cdots, O e_{n}\right\}, l s, u s\right\} ; & 1 \leqslant k \leqslant N_{s}, \\
& s t \in \mathbb{N}_{4}, \\
& l s \in \mathbb{N} \wedge l s \leqslant N_{s t}, \\
& u s \in \mathbb{N} \wedge 0<u s \leqslant N_{s t}, l s \leqslant u s
\end{aligned}
$$

Each floor $(F$, Eq. A.5 $)$ is a rectangle defined by its top-left corner $x$ and $y$ coordinates $(f x$ and $f y$, respectively), width $(f w)$, and depth $(f d)$.

$$
\begin{aligned}
F_{l}\{f x, f y, f w, f d\} ; & 1 \leqslant l \leqslant N_{f}, \\
& f x \in \mathbb{R}, \\
& f y \in \mathbb{R}, \\
& f w \in \mathbb{R} \wedge 0<f w, \\
& f d \in \mathbb{R} \wedge 0<f d
\end{aligned}
$$

The exterior opening (Oe, Eq. A.6) $)$ is a vector of values where oet defines the opening type (oet $=0$ is a void, oet $=1$ a door, oet $=2$ a window, and oet $=3$ a gate), oeo is the opening orientation ( $о e o=0$ is oriented to North, oeo $=1$ to East, oeo $=2$ to South, and oeo $=3$ to West), oea is the space floor rectangle number that the opening belongs to $\left(N f_{\text {oea }}\right.$ is the total number of floor objects in space $S_{\text {oea }}$ ), oew is the opening width, oeh is the opening height, oev is the opening vertical position, and oep is the relative position in the exterior wall of the oea floor rectangle side $(e o o)$.

$$
\begin{array}{ll}
\text { Oe }\{\text { oet }, \text { oeo, oea }, \text { oew }, \text { oeh, oev, oep }\} ; \quad & \leqslant m \leqslant N_{\text {eo }}, \\
\text { oet } \in \mathbb{N}_{4}, & \\
\text { oeo } \in \mathbb{N}_{4}, \\
\text { oea } \in \mathbb{N} \wedge \text { oea } \leqslant N_{F_{\text {oea }},}, \\
\text { oew } \in \mathbb{R} \wedge 0<\text { oew, } \\
\text { oeh } \in \mathbb{R} \wedge 0<\text { oeh }, \\
\text { oev } \in \mathbb{R} \wedge 0 \leqslant \text { oev }, \\
\text { oep } \in \mathbb{R} \wedge 0 \leqslant \text { oep } \leqslant 1
\end{array}
$$

The interior opening (Oi, Eq. A.7) object defines the indoor connection between spaces. When one of the spaces is a negative space, the interior opening is treated as an exterior opening $(O e)$. Similarly, this object is a vector where oit defines the opening type (oit $=0$ is a void, oit $=1$ a door, and oit $=2$ a window), oia is the space floor rectangle number that the opening connects from $\left(N f_{\text {oia }}\right.$ is the total number of floor objects in space $\left.S_{\text {oia }}\right)$, oib is the space floor rectangle 
number that the opening connects to $\left(N f_{\text {oib }}\right.$ is the total number of floor objects in space $\left.S_{\text {oib }}\right)$, oiw is the opening width, oih is the opening height, oiv is the opening vertical position, and oip is the relative position in the interior wall that is common to both spaces $\left(S_{\text {oia }}\right.$ and $\left.S_{\text {oib }}\right)$. If the opening width (oiw) is set to zero, this object is treated as a simple adjacency between those two spaces.

$$
\begin{aligned}
\text { Oin }\{\text { oit, oia, oib, oiw, oih, oiv, oip }\} ; & 1 \leqslant n \leqslant N_{\text {io }}, \\
& \text { oit } \in \mathbb{N}_{3}, \\
& \text { oia } \in \mathbb{N} \wedge \text { oia } \leqslant N_{F_{\text {oia }}} \text {, from space } S_{\text {oia }}, \\
& \text { oib } \in \mathbb{N} \wedge \text { oib } \leqslant N_{F_{\text {oib }}, \text { to space } S_{\text {oib }},} \\
& \text { oiw } \in \mathbb{R} \wedge 0 \leqslant \text { oiw, } \\
& \text { oih } \in \mathbb{R} \wedge 0<\text { oih, } \\
& \text { oiv } \in \mathbb{R} \wedge 0 \leqslant \text { oiv, } \\
& \text { oip } \in \mathbb{R} \wedge 0 \leqslant \text { oip } \leqslant 1
\end{aligned}
$$

The individuals' fitness is assessed according to several groups of objectives. Each group has its penalty function $\left(f_{c}\right)$, which is multiplied by its corresponding weight $\left(w_{c}\right)$. In total, there are 18 functions summed in a weighted cost function to be minimized (see Eq. (A.8)). Each function is triggered when its weight is different from 0 and the user constrains, necessary for that function to work, are defined.

$$
\begin{aligned}
\min f_{i}(x)= & \sum_{c=1}^{3} w_{c} \cdot f_{c}\left(I_{i}\right)+ \\
& \sum_{c=4}^{8} \sum_{j}^{N_{s t}} w_{c} \cdot f_{c}\left(L_{j}\right)+ \\
& \sum_{c=9}^{12} \sum_{k}^{N_{s}} w_{c} \cdot f_{c}\left(S_{k}\right)+ \\
& \sum_{c=13}^{16} \sum_{l}^{N_{e o}+N_{i o}} w_{c} \cdot f_{c}\left(O_{l}\right)+ \\
& \sum_{m}^{N_{e o}} w_{17} \cdot f_{17}\left(O e_{m}\right)+ \\
& \sum_{n}^{N_{i o}} w_{18} \cdot f_{18}\left(O i_{n}\right)
\end{aligned}
$$

The first penalty function (function $f_{1}$ multiplied by its weight $w_{1}$ ) calculates the alignments of the floor plan or clusters of spaces. If the alignment object is a point, the Manhattan distance from the bounding box center of the element or group of elements to the given point is measured. If the alignment object is a line, the Euclidean distance from one of the selected edges of the bounding box to the line is calculated. Lastly, if the alignment object is a rectangle, the function calculates if the bounding box fits exactly over a given rectangle defined by two opposite points. As the user 
can define one or more alignment objects, the function $\left(f_{a l}\right)$ returns the sum of all alignments. Eq. A.9 defines this penalty function.

$$
\begin{gathered}
f_{1}\left(I_{i}\right)=f_{a l}\left(I_{i}, C_{i}^{a l}\right)+\sum_{o=1}^{N_{a c}} f_{a l}\left(G_{o}^{a}, C_{o}^{a l}\right) \\
f_{a l}(A o)= \begin{cases}f_{p f p}\left(A o, C^{p f p}\right) & \text { if } A o \text { is a point } \\
f_{a f p}\left(A o, C^{a o}, C^{a s}, C^{a v}\right) & \text { if } A o \text { is a line } \\
f_{r f p}\left(A o, C^{t l}\right)+f_{r f p}\left(A o, C^{b r}\right) & , \text { if } A o \text { is a rectangle }\end{cases}
\end{gathered}
$$

The second penalty function (Eq. A.11), $f_{2}$, weight $w_{2}$ ) calculates the individual gross and construction areas ( $f_{g a}$ and $f_{c a}$, respectively), and if these are above the maximum limits for gross and construction areas ( $C^{g a}$ and $C^{c a}$, respectively), the square root of the excess value (of each area) is summed. This function is only triggered when the user specifies at least one of these area limits. The purpose of this function is to satisfy area requirements, such as defined by the municipality. Eq. A.11 depicts this function.

$$
\begin{aligned}
f_{2}\left(I_{i}\right)= & \sqrt{f_{\text {lga }}\left(I_{i}\right)}+\sqrt{f_{\text {lca }}\left(I_{i}\right)} \\
& f_{\text {lga }}\left(I_{i}\right)=f_{\text {ga }}\left(I_{i}\right)-C^{g a}, \text { if } C^{g a}<f_{g a}\left(I_{i}\right) \\
& f_{\text {lca }}\left(I_{i}\right)=f_{c a}\left(I_{i}\right)-C^{c a}, \text { if } C^{c a}<f_{c a}\left(I_{i}\right)
\end{aligned}
$$

The third penalty function (Eq. A.14, $f_{3}$, weight $w_{3}$ ) determines the individual gross and construction areas of the floor plan $\left(f_{g a}\right.$ and $f_{c a}$, respectively), and if these are below the maximum limit of gross and construction areas $\left(C^{g a}\right.$ and $C^{c a}$, respectively), the square root of the difference of each area is summed. This function is only activated when the user specifies at least one of these areas' limits. The goal is to maximize the building construction areas.

$$
\begin{aligned}
f_{3}\left(I_{i}\right)= & \sqrt{f_{f g a}\left(I_{i}\right)}+\sqrt{f_{f c a}\left(I_{i}\right)} \\
& f_{f g a}\left(I_{i}\right)=C^{g a}-f_{g a}\left(I_{i}\right), \text { if } f_{g a}\left(I_{i}\right)<C^{g a} \\
& f_{f c a}\left(I_{i}\right)=C^{c a}-f_{c a}\left(I_{i}\right), \text { if } f_{c a}\left(I_{i}\right)<C^{c a}
\end{aligned}
$$

When the user specifies a building boundary, the boundary in each story helps determine the maximum story area $\left(C_{j}^{s g a}\right)$. The fourth penalty function (Eq. A.17), $f_{4}$, weight $w_{4}$ ) calculates 
the difference between the story area and the $C_{j}^{s g a}$, when the former exceeds the latter, and takes the square root of the result. This function aims at to fill all the available area in the story by the rooms.

$$
f_{4}\left(L_{j}\right)=\sqrt{C_{j}^{s g a}-f_{s g a}\left(L_{j}\right)}, \text { if } f_{s g a}\left(L_{j}\right)<C_{j}^{s g a}
$$

In the fifth penalty function (Eq. A.18), $f_{5}$, weight $w_{5}$ ), the voids' dimensions (width and height; $\left.f_{c m p}\right)$ in the cluster $\left(G_{g}\right)$ bounding rectangle, which bounds spaces in the story $\left(L_{j}\right)$, are summed up. The purpose is to gather together the spaces and improve floor plans compactness.

$$
f_{5}\left(L_{j}\right)=\sum_{g}^{N_{c}} f_{c m p}\left(G_{g}, L_{j}\right)
$$

When the user specifies a building boundary, the sixth penalty function (Eq. A.19), $f_{6}$, weight $w_{6}$ ) calculates the Manhattan distance $\left(f_{\text {ovf }}\right)$ of the story spaces $\left(L_{j}\right)$ if these are outside of the story boundary $\left(B_{j}\right)$. This function is valuable when the building shape is defined or in a renovation scenario of existing buildings to force spaces to be within the building limits.

$$
f_{6}\left(L_{j}\right)=\sum_{k}^{N_{s}} f_{o v f}\left(B_{j}, S_{k}\right), \text { if } C_{k}^{s l} \leqslant j \leqslant C_{k}^{s u}
$$

To prevent overlapping of spaces that serve the same story $\left(L_{j}\right)$, the seventh penalty function (Eq. A.20), $f_{7}$, weight $\left.w_{7}\right)$ sums the minimum distances to prevent overlapping $\left(f_{\text {ovl }}\right)$ of a space $\left(S_{k}\right)$ with other spaces $\left(S_{k_{1}}\right)$ in the same story $\left(L_{j}\right)$, adjacent buildings $\left(A_{a}\right)$, vegetation $\left(V_{v}\right)$, and terrain $\left(T_{t}\right)$. The minimum distance corresponds to the $x$ - or $y$-coordinate path distance to avoid overlapping.

$$
\begin{aligned}
f_{7}\left(L_{j}\right)=\sum_{k}^{N_{s}}( & \sum_{k_{1}}^{N_{s}} f_{o v l}\left(S_{k}, S_{k_{1}}\right)+ \\
& \sum_{a}^{N_{a}} f_{o v l}\left(S_{k}, A_{a}\right)+ \\
& \sum_{v}^{N_{v}} f_{o v l}\left(S_{k}, V_{v}\right)+ \\
& \left.\sum_{t}^{N_{t}} f_{o v l}\left(S_{k}, T_{t}\right)\right), \text { if } C_{k}^{s l} \leqslant j \leqslant C_{k}^{s u} \wedge C_{k_{1}}^{s l} \leqslant j \leqslant C_{k_{1}}^{s u}
\end{aligned}
$$

In the eighth penalty function (Eq. A.21), $f_{8}$, weight $w_{8}$ ), the relative position of a space in the story is evaluated $\left(f_{s r p}\right)$, by determining the distance of the space $\left(S_{k}\right)$ to the boundary of the 
story $\left(L_{j}\right)$ that it belongs to. The space position can be at the North, East, South, or West side of the story $\left(C_{k}^{s r p}\right)$.

$$
f_{8}\left(L_{j}\right)=\sum_{k}^{N_{s}} f_{s r p}\left(L_{j}, S_{k}, C_{k}^{s r p}\right), \text { if } C_{k}^{s l} \leqslant j \leqslant C_{k}^{s u} \wedge C_{k}^{s r p} \in\{\text { North, East, South, West }\}
$$

The ninth penalty function (Eq. A.22, $f_{9}$, weight $w_{9}$ ) aims to reduce the size of circulation spaces $\left(C_{k}^{s f}\right)$. When those spaces are corridors or halls, the minimum admissible space size $\left(C_{k}^{s s}\right)$ is subtracted with the space's side dimensions and the differences are summed up. In the case of being stairs or elevators, the dimensions of the space are only summed.

$$
f_{9}\left(S_{k}\right)= \begin{cases}f_{c i r}\left(S_{k}\right)-2 \cdot C_{k}^{s s} & , \text { if } S_{k} \text { horizontal circulation } \\ f_{c i r}\left(S_{k}\right) & , \text { if } S_{k} \text { vertical circulation }\end{cases}
$$

The spaces' dimensions are assessed by the tenth penalty function (Eq. A.23), $f_{10}$, weight $\left.w_{10}\right)$, which consists in determining if the smaller side, the larger side, and area of the space $\left(S_{k}\right)$ determined by the functions $f_{s s}, f_{l s}$, and $f_{s a}$, respectively - satisfy the minimum side dimension $\left(C^{s s}\right)$, the side ratios $\left(C^{s s r}\right.$ for the smallest side and $C^{l s r}$ for the largest side), and the minimum area $\left(C^{s a}\right)$ constraints.

$$
\begin{aligned}
f_{10}\left(S_{k}\right)= & f_{l s s}\left(S_{k}\right)+f_{u s s}\left(S_{k}\right)+f_{l l s}\left(S_{k}\right)+f_{u l s}\left(S_{k}\right)+f_{a l}\left(S_{k}\right) \\
& f_{l s s}\left(S_{k}\right)=\frac{\left(C_{k}^{s s}-f_{s s}\left(S_{k}\right)\right)^{3}}{10^{3.40}}, \text { if } f_{s s}\left(S_{k}\right)<C_{k}^{s s} \\
f_{u s s}\left(S_{k}\right) & =\frac{\left(f_{s s}\left(S_{k}\right)-\left(C_{k}^{s s} \cdot C_{k}^{s s r}\right)\right)^{3}}{10^{3.40}}, \text { if } C_{k}^{s s} \cdot C_{k}^{s s r}<f_{s s}\left(S_{k}\right) \\
f_{l l s}\left(S_{k}\right) & =\frac{\left(C_{k}^{s s}-f_{l s}\left(S_{k}\right)\right)^{3}}{10^{4.42}}, \text { if } f_{l s}\left(S_{k}\right)<C_{k}^{s s} \\
f_{u l s}\left(S_{k}\right) & =\frac{\left(f_{l s}\left(S_{k}\right)-\left(C_{k}^{s s} \cdot C_{k}^{s s r} \cdot C_{k}^{l s r}\right)\right)^{3}}{10^{4.42}}, \text { if } C_{k}^{s s} \cdot C_{k}^{s s r} \cdot C_{k}^{l s r}<f_{l s}\left(S_{k}\right) \\
f_{a l}\left(S_{k}\right) & =\sqrt{C_{k}^{s a}-f_{s a}\left(S_{k}\right)}, \text { if } f_{s a}\left(S_{k}\right)<C_{k}^{s a}
\end{aligned}
$$

The eleventh penalty function (Eq. A.29), $f_{11}$, weight $w_{11}$ ) assesses if a space $\left(S_{k}\right)$ aligns over specified objects $\left(C_{k}^{a l}\right)$ according to the alignment function $\left(f_{a l}\right)$.

$$
f_{11}\left(S_{k}\right)=f_{a l}\left(S_{k}, C_{k}^{a l}\right)
$$

The twelfth penalty function (Eq. A.30, $f_{12}$, weight $w_{12}$ ) compares dimensions of two spaces 
$\left(S_{k}\right.$ and $\left.S_{k_{1}}\right)$ when the relative importance of the two spaces $\left(C_{k}^{r i}\right.$ and $\left.C_{k_{1}}^{r i}\right)$ is different. The function returns the difference between the square root of the most important space area and the square root of the least important space area. The aim of this function is to allow the user to specify an internal hierarchy of spaces, independently of their dimensional constraints.

$$
\begin{aligned}
f_{12}\left(S_{k}\right)= & \sum_{k_{1}}^{N_{s}} f_{r i}\left(S_{k}, S_{k_{1}}\right), \text { if } C_{k}^{r i} \neq C_{k_{1}}^{r i} \text { and if } S_{k} \wedge S_{k_{1}} \neq \text { vertical circulation } \\
& f_{r i}\left(S_{k}, S_{k_{1}}\right)= \begin{cases}1.1 \sqrt{f_{s a}\left(S_{k_{1}}\right)}-\sqrt{f_{s a}\left(S_{k}\right)}, \text { if } f_{s a}\left(S_{k}\right)<1.1 \sqrt{f_{s a}\left(S_{k_{1}}\right)} \wedge C_{k_{1}}^{r i}<C_{k}^{r i} \\
1.1 \sqrt{f_{s a}\left(S_{k}\right)}-\sqrt{f_{s a}\left(S_{k_{1}}\right)} \quad, \text { if } f_{s a}\left(S_{k_{1}}\right)<1.1 \sqrt{f_{s a}\left(S_{k}\right)} \wedge C_{k}^{r i}<C_{k_{1}}^{r i}\end{cases}
\end{aligned}
$$

The thirteenth penalty function (Eq. A.32), $f_{13}$, weight $w_{13}$ ) determines if clear areas of an opening $\left(O_{l}\right)$ overlap other objects, such as spaces $\left(S_{k}\right)$, openings clear areas $\left(O_{l_{1}}\right)$, adjacent buildings $\left(A_{a}\right)$, vegetation $\left(V_{v}\right)$, and terrain $\left(T_{t}\right)$. An opening clear area is the vacant space that is required from each side of a door, window, or other element to prevent obstruction. The function returns the sum of the dimensions of the overlapping areas.

$f_{13}\left(O_{l}\right)=\sum_{k}^{N_{s}} f_{o v l}\left(O_{l}, S_{k}\right)+\sum_{l_{1}}^{N_{e o}+N_{i o}} f_{o v l}\left(O_{l}, O_{l_{1}}\right)+\sum_{a}^{N_{a}} f_{o v l}\left(O_{l}, A_{a}\right)+\sum_{v}^{N_{v}} f_{o v l}\left(O_{l}, V_{v}\right)+\sum_{a}^{N_{t}} f_{o v l}\left(O_{l}, T_{t}\right)$

In the fourteenth penalty function (Eq. A.33, $f_{14}$, weight $w_{14}$ ), the accessibility areas of the openings are checked. In the case of interior openings, the accessibility areas in the space that gives passage to $\left(C_{l}^{o i a}\right)$ and in the space downstream the passage $\left(C_{l}^{o i b}\right)$ are evaluated if these overflow the spaces' floors, by summing up the dimensions of the overflown areas. Additionally, if the downstream space accessibility area overlaps the accessibility areas of the other space openings, the overlapping area dimensions are also summed up. In the case of exterior openings, only the overflow of the accessibility area in the space $\left(C_{l}^{o s}\right)$ that the opening belongs to is calculated.

$$
f_{14}\left(O_{l}\right)= \begin{cases}f_{\text {ovf }}\left(O_{l}, C_{l}^{\text {oia }}\right)+f_{\text {ovf }}\left(O_{l}, C_{l}^{\text {oib }}\right)+\sum_{n}^{N_{i o}} f_{\text {ovl }}\left(O_{l}, O_{n}\right) & , \text { if } O_{l} \text { is an interior opening } \\ f_{\text {ovf }}\left(O_{l}, C_{l}^{o s}\right) & , \text { if } O_{l} \text { is an exterior opening }\end{cases}
$$

The fifteenth penalty function (Eq. A.34), $f_{15}$, weight $w_{15}$ ) evaluates the width of the openings $\left(O_{l}\right)$ and calculates the difference to the required dimension $\left(C_{l}^{o i w}\right.$ for interior openings or $C_{l}^{o e w}$ for exterior openings) when the former is smaller. Additionally, in the case of exterior windows, 
the window-to-floor ratio of the space $\left(C_{l}^{o s}\right)$ is used to determine the minimum window width necessary. The difference is then calculated if the window width is smaller than this value.

$$
f_{15}\left(O_{l}\right)= \begin{cases}f_{\text {owd }}\left(O_{l}, C_{l}^{\text {oiw }}\right) & , \text { if } O_{l} \text { is an interior opening } \\ f_{\text {owd }}\left(O_{l}, C_{l}^{\text {oew }}\right)+f_{w f r}\left(O_{l}, C_{l}^{\text {os }}\right) & , \text { if } O_{l} \text { is an exterior opening }\end{cases}
$$

The user may define a set of alignments for an opening $\left(O_{l}\right)$. In this case, the sixteenth penalty function (Eq. A.35, $f_{16}$, weight $w_{16}$ ) calculates and sums the distances of the opening to the object $\left(f_{a l}\right)$.

$$
f_{16}\left(O_{l}\right)=f_{a l}\left(O_{l}, C_{l}^{a l}\right)
$$

The seventeenth penalty function (Eq. A.36), $f_{17}$, weight $w_{17}$ ) determines if an exterior opening is facing the right orientation (North, East, South, or West) set by the user $\left(C_{m}^{o e o}\right)$. If not, the function returns the opening width as penalty.

$$
f_{17}\left(O e_{m}\right)=f_{\text {oeo }}\left(O e_{m}, C_{m}^{o e o}\right), \text { if oeo } \neq C_{m}^{o e o}
$$

The last and eighteenth penalty function (Eq. A.37), $f_{18}$, weight $w_{18}$ ) evaluates the interior connectivity by calculating the Manhattan distance between two spaces $\left(C_{n}^{\text {oia }}\right.$ and $\left.C_{n}^{\text {oib }}\right)$ if an interior opening $\left(O i_{n}\right)$ cannot be placed in the wall common to both spaces. If the interior opening width $\left(C_{n}^{\text {oiw }}\right)$ is zero, then the function works as adjacency only.

$$
f_{18}\left(O i_{n}\right)=f_{i o c}\left(O i_{n}, C_{n}^{o i a}, C_{n}^{o i b}, C_{n}^{o i w}\right)
$$

